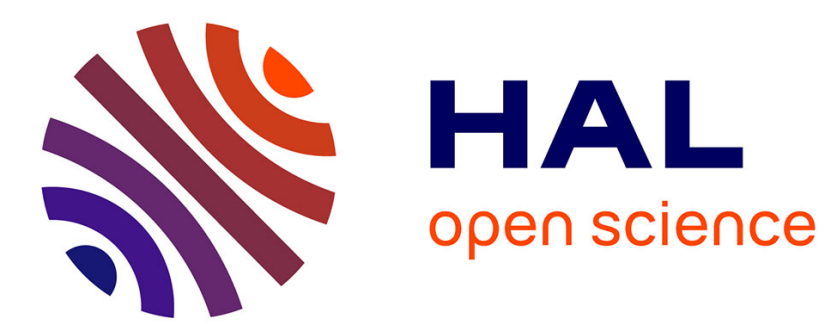

\title{
Increasing the Cytotoxicity of Ru(II) Polypyridyl Complexes by tuning the Electronic Structure of Dioxo Ligands
}

Anna Notaro, Marta Jakubaszek, Nils Rotthowe, Federica Maschietto, Robin Vinck, Patrick S Felder, Bruno Goud, Mickaël Tharaud, Ilaria Ciofini, Fethi Bedioui, et al.

\section{To cite this version:}

Anna Notaro, Marta Jakubaszek, Nils Rotthowe, Federica Maschietto, Robin Vinck, et al.. Increasing the Cytotoxicity of $\mathrm{Ru}(\mathrm{II})$ Polypyridyl Complexes by tuning the Electronic Structure of Dioxo Ligands. Journal of the American Chemical Society, In press, 10.1021/jacs.9b12464 . hal-02509374

\section{HAL Id: hal-02509374 \\ https://hal.science/hal-02509374}

Submitted on 16 Mar 2020

HAL is a multi-disciplinary open access archive for the deposit and dissemination of scientific research documents, whether they are published or not. The documents may come from teaching and research institutions in France or abroad, or from public or private research centers.
L'archive ouverte pluridisciplinaire HAL, est destinée au dépôt et à la diffusion de documents scientifiques de niveau recherche, publiés ou non, émanant des établissements d'enseignement et de recherche français ou étrangers, des laboratoires publics ou privés. 


\section{Increasing the Cytotoxicity of $\mathrm{Ru}(\mathrm{II})$ Polypyridyl Complexes by tuning the Electronic Structure of Dioxo Ligands}

Anna Notaro, ${ }^{a}$ Marta Jakubaszek,,${ }^{a, b}$ Nils Rotthowe, ${ }^{c}$ Federica Maschietto, ${ }^{d}$ Robin Vinck, ${ }^{a}$ Patrick S. Felder, ${ }^{a}$ Bruno Goud, ${ }^{b}$ Mickaël Tharaud, ${ }^{e}$ Ilaria Ciofini, ${ }^{d}$ Fethi Bedioui, ${ }^{f}$ Rainer F. Winter, ${ }^{c}$ and Gilles Gasser ${ }^{a, *}$

a Chimie ParisTech, PSL University, CNRS, Institute of Chemistry for Life and Health Sciences, Laboratory for Inorganic Chemical Biology, F-75005 Paris, France.

b Institut Curie, PSL University, CNRS UMR 144, Paris, France.

c Department of Chemistry, University of Konstanz, Universitätsstrasse 10, D-78457 Konstanz, Germany.

d Chimie ParisTech, PSL University, CNRS, Institute of Chemistry for Life and Health Sciences, Chemical Theory and Modelling Group, F-75005 Paris, France.

e Université de Paris, Institut de physique du globe de Paris, CNRS, F-75005 Paris, France.

f Chimie ParisTech, PSL University, CNRS, Institute of Chemistry for Life and Health Sciences, Team Synthèse, Electrochimie, Imagerie et Systèmes Analytiques pour le Diagnostic, F-75005 Paris, France.

* Corresponding author: E-mail: gilles.gasser@chimeparistech.psl.eu; WWW: www.gassergroup.com; Phone: +331442756 02

ORCID Number

Anna Notaro: 0000-0003-0148-1160

Marta Jakubaszek: 0000-0001-7590-2330

Nils Rotthowe: 0000-0002-0073-136X 
Federica Maschietto: 0000-0002-5995-2765

Patrick S. Felder: 0000-0003-2325-9026

Bruno Goud: 0000-0003-1227-4159

Fethi Bedioui: 0000-0002-0063-4412

Ilaria Ciofini: 0000-0002-5391-4522

Rainer F. Winter: 0000-0001-8381-0647

Gilles Gasser: 0000-0002-4244-5097

Keywords: Bioinorganic Chemistry, Cancer, DNA, Medicinal Inorganic Chemistry, Ruthenium. 


\section{Abstract}

Due to the great potential expressed by an anticancer drug candidate previously reported by our group, namely, Ru-sq ([Ru(DIP)2(sq)](PF6) (DIP: 4,7-diphenyl-1,10phenanthroline, sq: semiquinonate ligand), we describe in this work a structure-activity relationship (SAR) that involves a broader range of derivatives resulting from the coordination of different catecholate-type dioxo ligands to the same $\mathrm{Ru}(\mathrm{DIP})_{2}$ core. More in detail, we chose catechols carrying either electron-donating or electronwithdrawing groups EDG or EWG and investigated the physico-chemical and biological properties of their complexes. Several pieces of experimental evidences demonstrated that the coordination of catechols bearing EDGs led to deep red positively charged complexes 1-4 in which the preferred oxidation state of the dioxo ligand is the uninegatively charged semiquinonate. Complexes $\mathbf{5}$ and $\mathbf{6}$, on the other hand, are blue/violet neutral complexes, which carry an EWG substituted dinegatively charged catecholate ligand. The biological investigation of complexes 1-6 led to the conclusion that the difference in their physico-chemical properties has a strong impact on their biological activity. Thus, complexes 1-4 expressed much higher cytotoxicities than complexes 5 and 6. Complex 1 constitutes the most promising compound of the series and was selected for a more in-depth biological investigation. Apart from its remarkably high cytotoxicity ( $\mathrm{IC}_{50}=0.07-0.7 \mu \mathrm{M}$ in different cancerous cell lines) complex 1 was taken up by HeLa cells very efficiently by a passive transportation mechanism. Moreover, its moderate accumulation in several cellular compartments (i.e. nucleus, lysosomes, mitochondria and cytoplasm) is extremely advantageous in the search of a potential drug with multiple modes of action. Further DNA metalation and metabolic studies pointed to the direct interaction of complex 1 with DNA and to the severe impairment of the mitochondrial function. Multiple targets, together with its 
outstanding cytotoxicity, make complex $\mathbf{1}$ a valuable candidate in the field of chemotherapy research. Noteworthy, a preliminary biodistribution study on healthy mice demonstrated the suitability of complex $\mathbf{1}$ for further in vivo studies. 


\section{Introduction}

The worldwide approval of the anticancer drug cisplatin and later of carboplatin and oxaliplatin has made platinum-based drugs the leading compounds in the field of medicinal inorganic chemistry. ${ }^{1,2}$ However, the side-effects and resistance associated with these compounds have spurred numerous investigations into other metal-based drugs as potential chemotherapeutic agents against cancer. ${ }^{1,3-6}$ Ruthenium complexes are presently regarded as the successors/alternatives to the aforementioned platinum compounds. $^{7-14}$ Three ruthenium complexes were (i.e., NKP-1019 and NAMI-A, Figure 1) or are (i.e., IT-139, Figure 1) in clinical trials as chemotherapeutic agents. In addition, a Ru(II) polypyridyl complex, namely TLD-1433 (Figure 1) has just entered phase II of clinical trials as a photosensitizer for photodynamic therapy against bladder cancer. ${ }^{15-20} \mathrm{Ru}(\mathrm{II})$ polypyridyl complexes, have also been extensively studied for their cytotoxicity and sowed a great potential as chemotherapeutic agents. ${ }^{21-28}$ Recently, we reported a detailed study on a very promising $\mathrm{Ru}(\mathrm{II})$ polypyridyl complex, namely $\left[\mathrm{Ru}(\mathrm{DIP})_{2}(\mathrm{sq})\right]\left(\mathrm{PF}_{6}\right) \quad(\mathbf{R u}-\mathbf{s q}, \quad$ Scheme 1a), where $\mathrm{DIP}$ is 4,7-diphenyl-1,10phenanthroline and sq is a semiquinonate ligand. ${ }^{29}$ Semiquinonate (sq) is the product of the first one-electron oxidation of catecholate (cat) and can be further oxidized to quinone (q) (Scheme 1b). ${ }^{30,31}$ Catechol(ate) and its redox congeners semiquinonate and 1,2-benzoquinone are pivotal examples for the class of 'non-innocent' ligands. ${ }^{32}$ This definition is more appropriately referring to a pair of a metal ion and a ligand which are both redox-active and whose frontier orbitals are strongly mixed, defying an unambiguous assignment of redox states to either component. ${ }^{32}$ Catechols are also considered as pan-assay interference compounds (PAINS) due to their chelating and redox properties. ${ }^{33}$ 


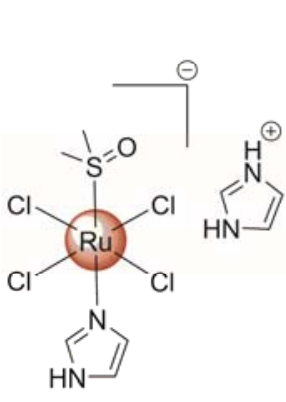

NAMI-A

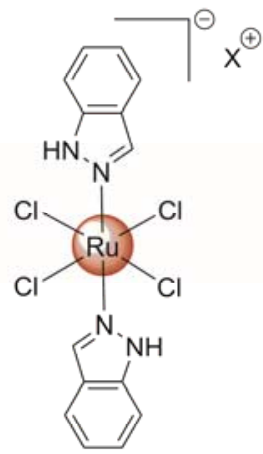

IT-139 (formerly NKP-1339) $X=\mathrm{Na}^{\oplus}$

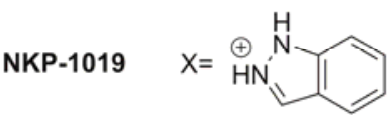

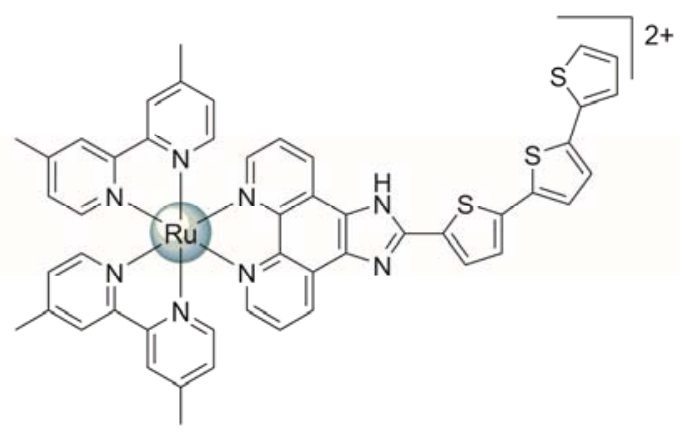

TLD-1433

Figure 1. Chemical structures of Ruthenium complexes that were (i.e., NKP-1019 and NAMI-A, Figure 1) or are (i.e., IT-139 and TLD-1433) in clinical trials.

Ru-sq was, to the best of our knowledge, the first $\mathrm{Ru}(\mathrm{II})$ polypyridyl complex carrying a semiquinonate moiety, which was investigated in depth as an anticancer drug candidate. We could demonstrate that it is a valuable option as a chemotherapeutic agent, both in vitro and in vivo. Interestingly, its mechanisms of action involve more than one cellular target. This finding could potentially be a key feature to overcome resistance, which is an inherent problem for platinum-based anticancer drug candidates. ${ }^{29}$ Driven by the promising properties unveiled for Ru-sq, we undertook a structure-activity relationship (SAR) study, keeping the same $\mathrm{Ru}(\mathrm{II})$ polypyridyl core (i.e. $\mathrm{Ru}(\mathrm{DIP})_{2}$ ), but substituting the catechol-type dioxo ligand. Over the years, many studies have been performed focusing on the non-innocent character of different metal complexes both from an experimental and theoretical point of view. ${ }^{34-41}$ In 2006 , Wada and co-workers demonstrated how the oxidation state of the dioxo ligand in a given metal-coligand environment depends on the nature of its substituents. ${ }^{42}$ More specifically, the authors investigated a series of [Ru(OAc)(dioxolene)(terpy)] complexes with dioxo ligands carrying electron withdrawing (EWG) or electron 
donating (EDG) groups. ${ }^{42}$ In particular, they observed that due to the non-innocent nature of the dioxo ligand, all complexes lie on a continuum in between formal $\mathrm{Ru}^{\mathrm{II}}(\mathrm{sq})$ and $\mathrm{Ru}^{\mathrm{III}}(\mathrm{cat})$ descriptions, with an increase of the contribution of the $\mathrm{Ru}^{\mathrm{II}}(\mathrm{sq})$ form for complexes with an EDG-substituted dioxo ligand and vice versa.${ }^{42}$ Herein, we present, a new series of complexes carrying dioxo ligands substituted with EDGs or EWGs, namely $\quad\left[\mathrm{Ru}(\mathrm{DIP})_{2}(3\right.$-methoxysq) $]\left(\mathrm{PF}_{6}\right) \quad(\mathbf{1}), \quad\left[\mathrm{Ru}(\mathrm{DIP})_{2}\right.$ (3-methylsq) $]\left(\mathrm{PF}_{6}\right) \quad$ (2), $\left[\mathrm{Ru}(\mathrm{DIP})_{2}(4-\right.$ methylsq $\left.)\right]\left(\mathrm{PF}_{6}\right) \quad$ (3), $\quad\left[\mathrm{Ru}(\mathrm{DIP})_{2}\right.$ (4-tert-butylsq) $]\left(\mathrm{PF}_{6}\right)$ $\mathrm{Ru}(\mathrm{DIP})_{2}$ (tetrabromocat) (5) and $\mathrm{Ru}(\mathrm{DIP})_{2}$ (4-nitrocat) (6) (Scheme 1a), where DIP is 4,7-diphenyl-1,10-phenanthroline, 3-methoxysq is 3-methoxysemiquinonate, 3methylsq is 3-methylsemiquinonate, 4-methylsq is 4-methylsemiquinonate, 4-tertbutylsq is 4-tert-butylsemiquinonate, tetrabromocat is tetrabromocatecholate and 4nitrocat is 4-nitrocatecholate. The physico-chemical and biological properties of these compounds were investigated in depth. As described in the literature, ${ }^{34-41}$ the variation of the electron density on the dioxo ligand leads to the modification of its oxidation state when bound as a ligand. The different oxidation states of the dioxo ligands have a strong bearing on the physical properties of the complexes, affecting, among other parameters, their electronic structures and hence the charge state. Of note, we could unveil an interesting correlation between the oxidation state of the dioxo ligand and the biological activity of the complex. Complex 1 was found to be the most promising compound investigated. Its remarkable cytotoxicity in 2D models (IC50 values in the low nanomolar range) was confirmed in a more accurate 3D model, which led to further biological investigation. In the course of this work, we demonstrate how the mechanism of action of complex 1 involves multicellular targets. This remarkable peculiarity is considered a key factor to overcome one of the main drawbacks associated to chemotherapy treatments, which is the occurrence of resistance. Moreover, as most 
complexes of this kind, complex 1 displays poor water solubility. ${ }^{43}$ Recently, we reported the formation of colloids of Ru-sq and complex $\mathbf{1}$ in water-DMSO (1\% v/v) mixture, which could have been easily mistaken for solutions if no appropriate characterization had been performed. ${ }^{43}$ Poor aqueous solubility is usually considered a limitation for in vivo applications. However, in this study, we could demonstrate that with an appropriate formulation, complex $\mathbf{1}$ is able to distribute in healthy BALB/c mice, which renders it a suitable candidate for further in vivo studies.

a)

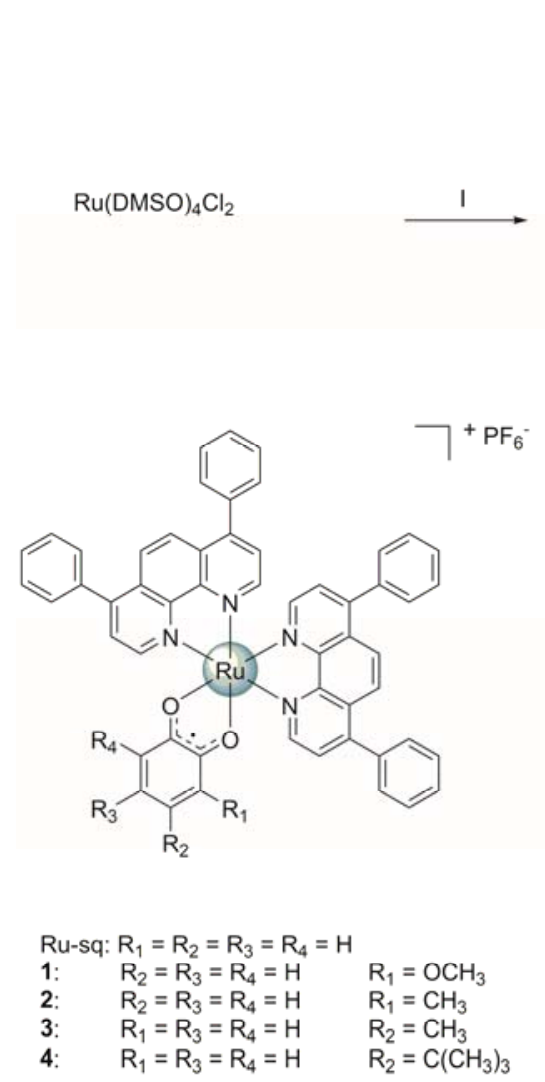

b)
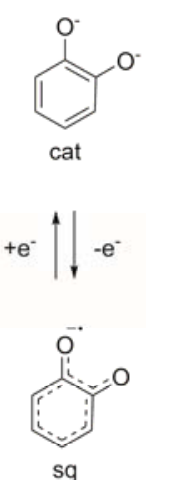

$+e^{-} \uparrow \mid-e^{-}$
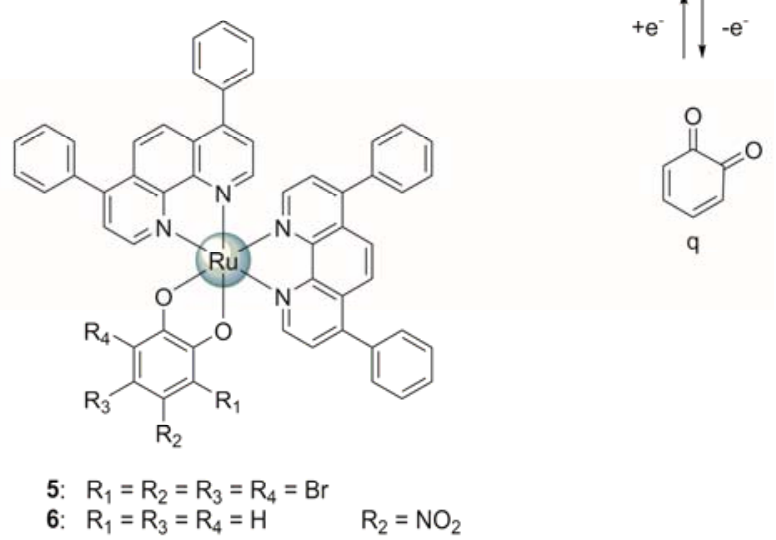

Scheme 1. a) Syntheses of complexes 1-6. I) DIP, LiCl, DMF, reflux, 24 h, 78\%; II) (i) $\mathrm{NaOH}, 3$-methoxycatechol (1), or 3-methylcatechol (2), or 4-methylcatechol (3) or 4tert-butylcatechol (4) 2-propanol, reflux, 24h; (ii) air, 2 h; (iii) $\mathrm{NH}_{4} \mathrm{PF}_{6}$, 2-propanol/ $\mathrm{H}_{2} \mathrm{O}$ (1:8), 19\% (Ru-sq), 23\% (1), 24\% (2), 29\% (3), 16\% (4). III) (i) $\mathrm{NaOH,}$ tetrabromocatechol (5) or 4-nitrocatechol (6), 2-propanol, reflux, 24h; (ii) air, 2 h; (iii) $\mathrm{NH}_{4} \mathrm{PF}_{6}, 2$-propanol/ $\mathrm{H}_{2} \mathrm{O}(1: 8), 54 \%(5), 27 \%(6)$. b) Catecholate (cat) and its oxidised forms, semiquinonate (sq) and quinone (q). 


\section{Results and Discussion}

\section{Synthesis and characterization of 1-6}

The synthesis of compounds 1-6 was achieved by adapting a previously reported procedure. ${ }^{29} \mathrm{Ru}(\mathrm{DIP})_{2} \mathrm{Cl}_{2}$ was obtained starting from the known $\mathrm{Ru}(\mathrm{DMSO})_{2} \mathrm{Cl}_{2}{ }^{44}$ as previously reported. ${ }^{45}$ This precursor complex was then refluxed under nitrogen atmosphere with the corresponding catechol derivative in the presence of $\mathrm{NaOH}$ in 2propanol overnight. ${ }^{29}$ Subsequently, the reaction vessel was opened to air for $2 \mathrm{~h}$ to allow for the final oxidation step. Interestingly, oxidation of the catecholate ligand to a semiquinonate occurred only for those complexes bearing catecholate ligands with EDG groups (complexes 1-4 in Scheme 1a). When the synthesis involved catechol derivatives bearing EWG groups, neutral complexes $(\mathbf{5 , 6 )}$ were generated. The drastic change of the electronic properties of the complexes studied in this work is also reflected by their color. EDG-containing derivatives are deep red solids, while EWGcontaining derivatives are blue/violet. UV/Vis/NIR spectroscopy in DMF solution (Figure 2) confirms the assignment of the EDG-substituted ligands as semiquinonates in that compounds 1-4 display a band at ca. 885-900 $\mathrm{nm}$. This absorption is characteristic for ruthenium-bis(diimine) complexes containing a semiquinonate ligand and is due to a $\mathrm{Ru}(\mathrm{II}) \rightarrow$ sq transition. ${ }^{46} \mathrm{~A}$ set of bands, which is responsible for the visual color impression of these compounds, is found in the range of 470 to $525 \mathrm{~nm}$. Based on literature data on similar compounds, this band can be ascribed to MLCT and LL'CT transitions $(\mathrm{MLCT}=$ metal-to-ligand charge-transfer; LL'CT = ligand-toligand' charge-transfer, electron transfer between a donor and an acceptor ligand). The two neutral compounds 5 and $\mathbf{6}$ are both characterized by a broad transition at $675 \mathrm{~nm}$ alongside two additional bands at ca. 600 and $500 \mathrm{~nm}$; both of which are responsible for their blue/violet color. Their similarity to the absorptions in the precursor complex 
$\mathrm{Ru}(\mathrm{DIP})_{2} \mathrm{Cl}_{2}$ is underlined by its similarly convoluted absorption profile with bands at 680,570 and $485 \mathrm{~nm}$. These data are in agreement with a previous report for the $\mathrm{Ru}(\text { bpy })_{2} \mathrm{Cl}_{2}$ analogue whose bands can be assigned as $\mathrm{Ru}(\mathrm{II}) \rightarrow$ DIP transitions. ${ }^{47} \mathrm{An}$ overview over the characteristic absorption bands of all compounds is provided in Table S1.

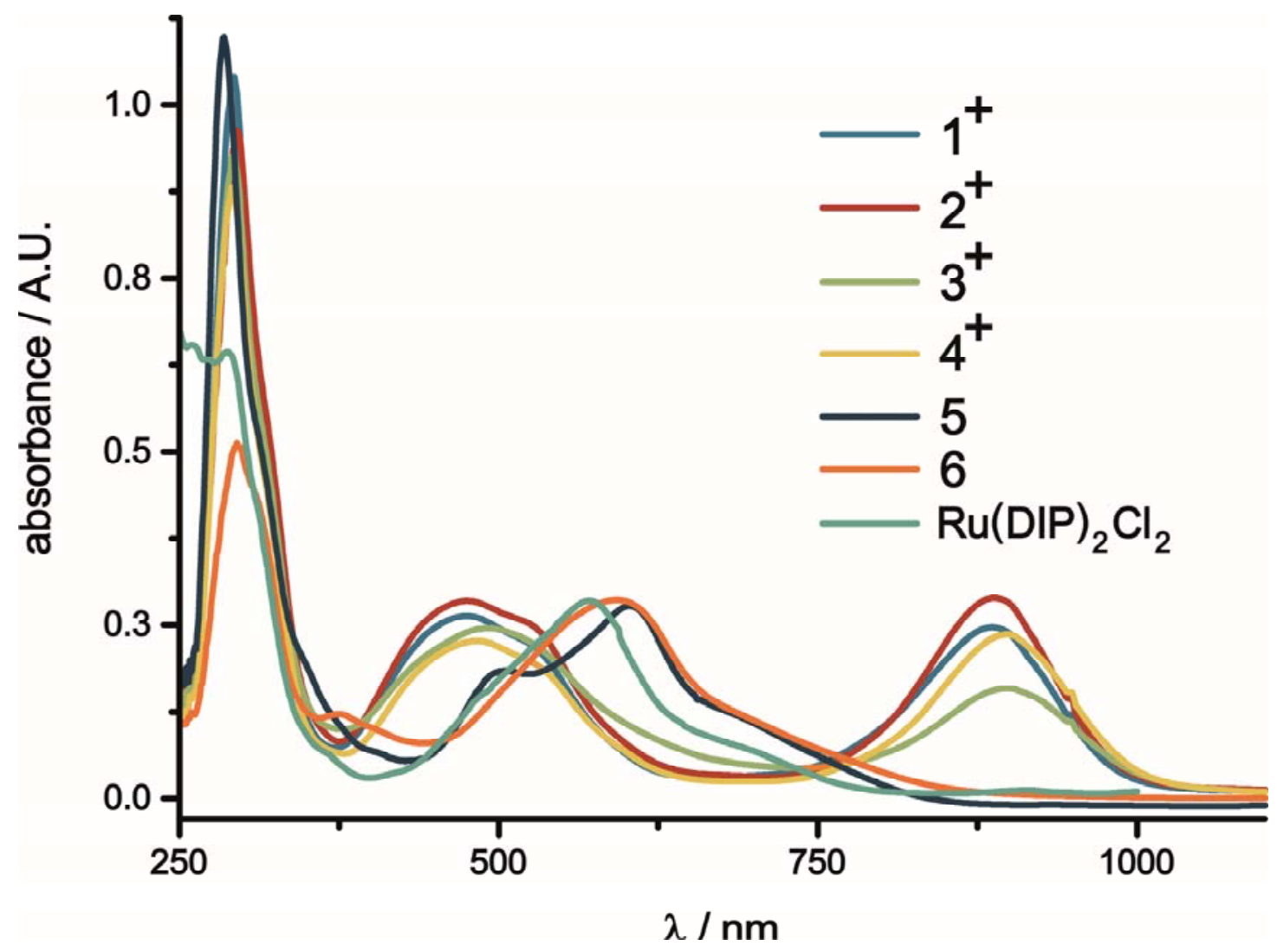

Figure 2. UV/Vis/NIR spectra in DMF solution of the complexes 1-6 and their precursor $\mathrm{Ru}(\mathrm{DIP})_{2} \mathrm{Cl}_{2}$.

The paramagnetic nature of compounds 1-4 was indirectly confirmed by their characteristically broadened ${ }^{1} \mathrm{H}-\mathrm{NMR}$ spectra (Figure S1). In contrast, compounds $\mathbf{5}$ and 6, whose purity was confirmed by elemental analysis, are neutral and formally diamagnetic. However, the proton NMR spectra also provided severely broadened resonances. The addition of zinc dust to the NMR tube, slightly improves the resolution 
of NMR signals which suggests the formation of paramagnetic species in solution (Figure S1 (5) and (6)). All complexes were characterized by ESI-MS, and their purity was verified by HPLC (Figure S2) and elemental analysis.

\section{EPR, (Spectro-)electrochemistry and Electronic Structures}

The oxidation state of the catecholate/semiquinonate ligand of complexes 1-6 was further investigated by electron paramagnetic resonance (EPR) spectroscopy, cyclic voltammetry $(\mathrm{CV})$, rotating disc electrode voltammetry (RDE) as well as UV/Vis/NIR spectroelectrochemistry and supported by density functional theory (DFT) calculations. Compounds 1-4 are, as obtained from the synthesis, EPR active. At room temperature, they display a rather broad, featureless, isotropic signal (Figure 3a), which becomes slightly anisotropic at lower temperatures and in the frozen glass (Figure S3). The substituents on the dioxo ligand and their positions seem to have only little influence on the locus and the distribution of the unpaired spin density. Thus, the $g_{\text {iso }}$ values of $1.9893,1.9891,1.9872$ and 1.9840 for $\mathbf{1}-\mathbf{4}$, respectively, are all close to the free electron value $g_{\mathrm{e}}$ of 2.0023 and differ only slightly from each other. 
a)

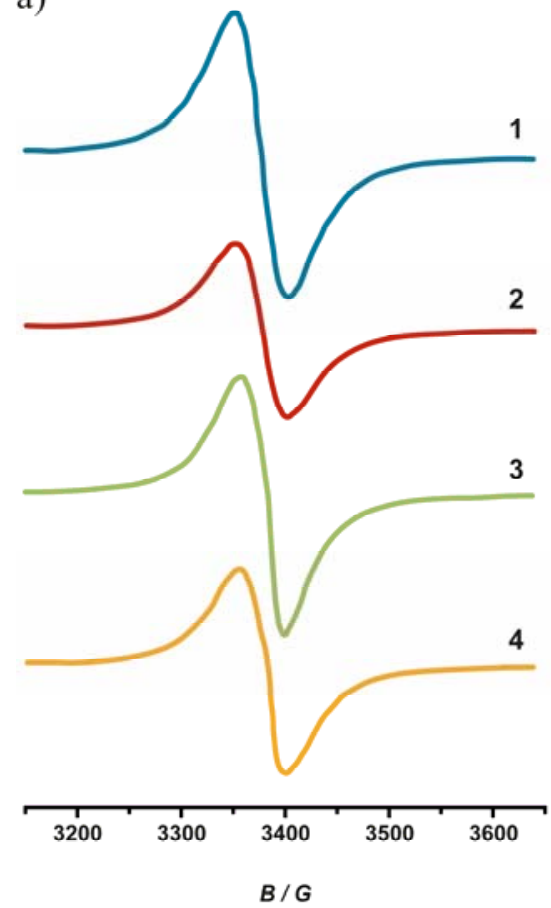

b)
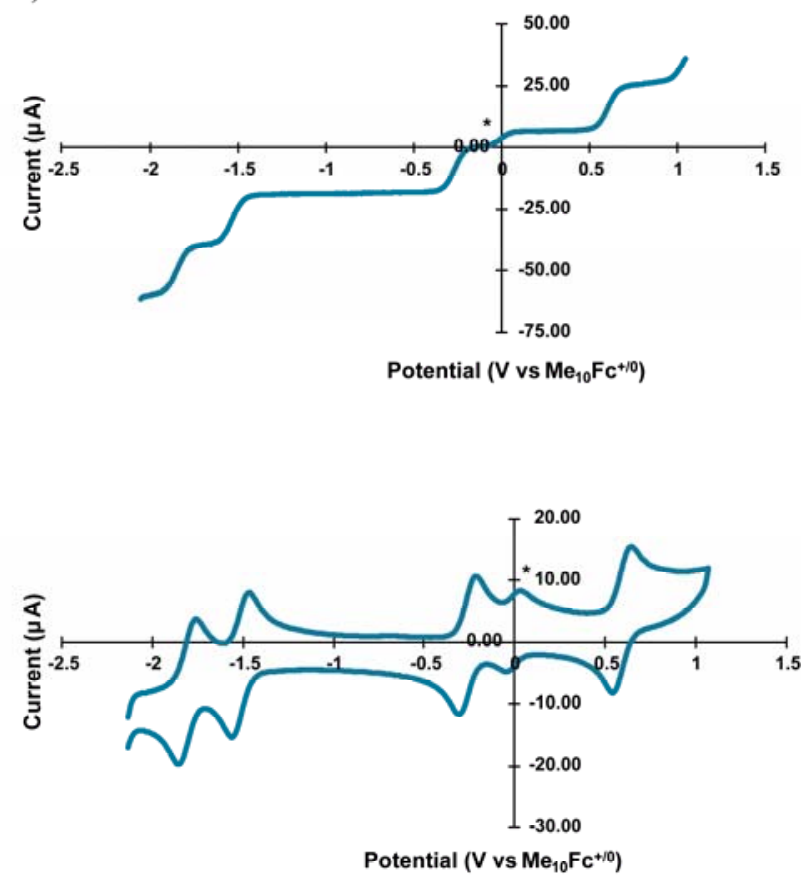

Figure 3. (a) EPR spectra of (from top to bottom) 1-4 at room temperature. (b) RDE and cyclic voltammograms of $\mathbf{1}$ (from -2.1 to $+1.0 \mathrm{~V}$ ) at a glassy carbon electrode in DMF (1 mM) containing $\mathrm{NBu}_{4} \mathrm{PF}_{6}(100 \mathrm{mM})$ as supporting electrolyte and decamethylferrocene as an internal standard $(0.25 \mathrm{mM})$. Data were recorded versus a saturated calomel electrode (SCE) at a scan rate of $100 \mathrm{mV} / \mathrm{s}$ and recalculated versus the $\mathrm{Me}_{10} \mathrm{Fc}^{0 /+}$ potential value $\left(E_{1 / 2}=0.040 \mathrm{~V} v s \mathrm{SCE}\right.$, feature marked with * in panel $\left.\mathrm{b}\right)$.

These data are also confirmed by the spin density distributions computed for compounds 1 and 3 reported in Table 1 and graphically depicted in Figure 4 (see the Experimental Section for computational details). Indeed, roughly $82 \%$ of the spin density is localized on the dioxo ligand with only limited delocalization onto the $\mathrm{Ru}$ center $(0.19|\mathrm{e}-|)$. Consequently, the computed $g$-tensors (reported as Table S2 in the SI) show very small anisotropies and shifts with respect to the free electron value. These results are consistent with the assumption that the 1,2-dioxo ligand can be formally represented by its semiquinonate form in the case of complexes $\mathbf{1 - 4}$. 
Table 1. Computed Mulliken spin densities on the different fragments of the cationic forms of the complexes.

\begin{tabular}{lllll}
\hline & 1 & \multicolumn{1}{l}{$\mathbf{3}$} & 50x & 6ox \\
\hline $\begin{array}{l}\text { dioxo } \\
\text { ligand }\end{array}$ & 0.8200 & 0.8268 & 0.6276 & 0.6003 \\
ancillary1 & -0.0090 & -0.0091 & -0.0077 & -0.0062 \\
ancillary2 & -0.0093 & -0.0089 & -0.0078 & -0.0098 \\
$\mathrm{Ru}$ & 0.1983 & 0.1913 & 0.3880 & 0.4157
\end{tabular}

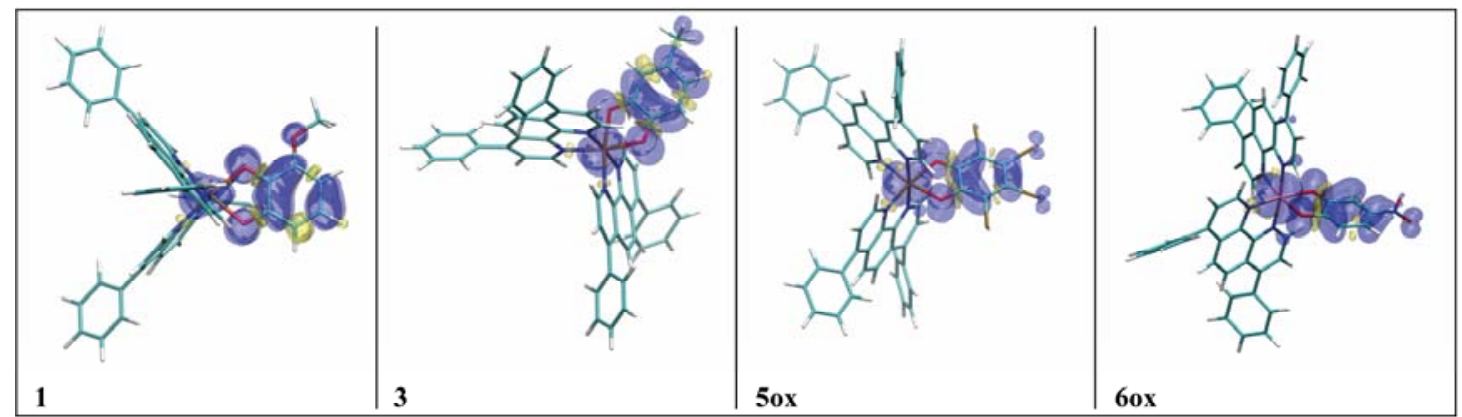

Figure 4. Isodensity plots of computed spin densities. Positive spin density corresponds to blue lobes.

To further investigate the electrochemical properties of compounds 1-4 and to obtain a better insight into the effect of the substituent's position and nature on the redox behavior of the complexes, cyclic voltammetry $(\mathrm{CV})$ and rotating disc electrode (RDE) analyses were performed. Complexes 1-4 display reduction as well as oxidation features in line with what we have reported in our previous work on Ru-sq, carrying the non-substituted semiquinonate ligand. ${ }^{29}$ Figure 3 shows the RDE and cyclic voltammograms of compound $\mathbf{1}$ while those of $\mathbf{2}-\mathbf{4}$ are available in the SI (Figure S4). Like all other complexes bearing EDG-substituted dioxo ligands, complex 1 exhibits four well-defined reversible redox processes. The RDE experiment shows four features 
with very similar limiting currents, which indicates that the same number of electrons are exchanged during every process. On the bases of our previous results, ${ }^{29}$ the redox process at $+0.595 \mathrm{~V}$ vs $\mathrm{Me}_{10} \mathrm{Fc}^{0 /+}$ can be attributed to the oxidation of $\mathrm{Ru}(\mathrm{II})$ to $\mathrm{Ru}(\mathrm{III})$ while the first reduction process at $-0.201 \mathrm{~V} v s \mathrm{Me}_{10} \mathrm{Fc}^{0 /+}$ can be attributed to the sq/cat redox process. UV/Vis/NIR-spectroelectrochemistry further supports this hypothesis. As evident from Figures 5a,b, reducing the complexes $\mathbf{1}$ or $\mathbf{2}$ at sufficiently negative potential yields spectra, whose general band structures closely resemble those of compounds $\mathbf{5}$ and $\mathbf{6}$. The observed red-shift with respect to the latter complexes is the result of the higher-lying donor orbitals (cat) and ( $\mathrm{Ru}(\mathrm{II}))$, which is due to electron-rich nature of dioxo ligand in 1. Oxidation to the corresponding dications (Figure 5c,d) 1ox and 2ox (denoted as $1^{2+}$ and $2^{2+}$ in Figure 5) leads to a general blue-shift of the Vis/NIR bands. The first visible transition is now found at $675 \mathrm{~nm}$ for both complexes. Compared to the $\left[\mathrm{Ru}(\mathrm{II})(\mathrm{bpy})_{2}(\mathrm{q})\right]^{2+}$ reference, this corresponds to a red-shift by 810 $\mathrm{cm}^{-1} \cdot{ }^{46}$ Adhering to the assignment of a $\mathrm{Ru}(\mathrm{II}) \rightarrow$ diimine MLCT transition this effect can be explained through the presence of a more extended $\pi$-system in the DIP ligand as compared to bpy. We note, however, that a $\mathrm{Ru}(\mathrm{III})$-sq scenario resulting in a dioxo ligand-to-metal charge-transfer (LMCT) is also possible. The strong electronic coupling between these two redox-active entities prohibits a clear assignment of redox states without additional experimental support or quantum chemical calculations. 

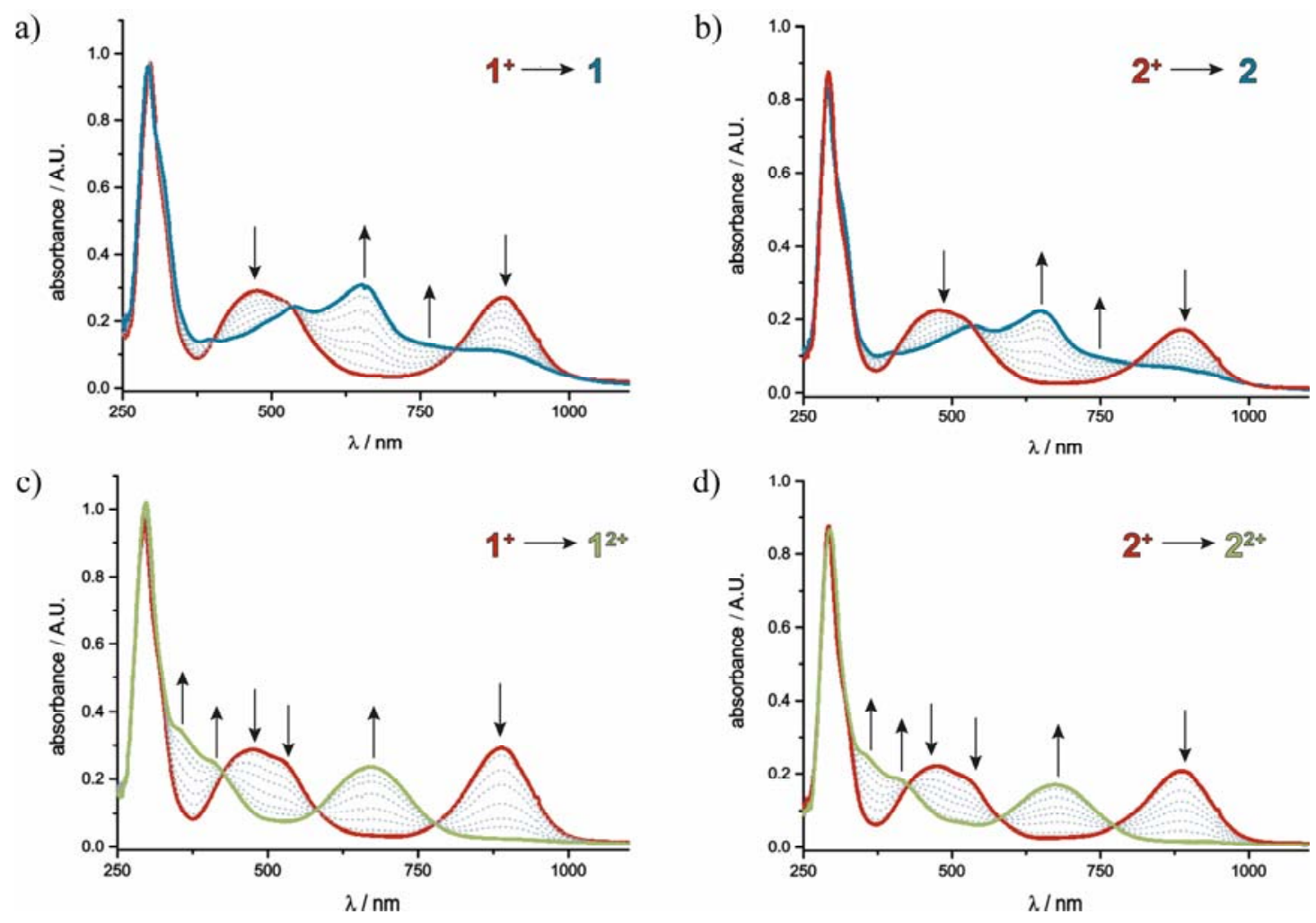

Figure 5. UV/Vis/NIR-spectroelectrochemistry data for compounds $\mathbf{1}$ and $\mathbf{2}$.

The additional two reduction processes at the more negative potentials of $-1.463 \mathrm{~V}$ and $-1.758 \mathrm{~V}$, respectively, are due to the stepwise one-electron reductions of the ancillary ligands (i. e. the $\mathrm{DIP}^{0 /-}$ couples). These processes were not further studied by spectroelectrochemical investigations due to the high reduction potentials and the irrelevance of these processes to the bioactivities of these complexes. Table 2 summarizes the redox potentials associated with compounds 1-4 and compares them to those of Ru-sq carrying the unsubstituted semiquinonate ligand (see full data in Table S3 of the Supporting Information). ${ }^{29}$ Comparing the results, it is clear that the presence of an EDG at the dioxo ligand increases the electron density on the metal center, hence shifting its redox process cathodically. These observations are perfectly in agreement with previous work from Wada and co-workers on the charge distribution between the ruthenium ion and the dioxo ligand. ${ }^{42}$ The stronger EDGs OMe and $t \mathrm{Bu}$ 
have the predictable effect of shifting the redox potentials of the sq/cat and $\mathrm{Ru}^{\mathrm{II} / \mathrm{III}}$ redox couples cathodically, with however, a different ordering of these couples for complexes 1 and 4.

Table 2. Electrochemical data for 1-4 and Ru-sq.

\begin{tabular}{|c|c|c|c|c|c|}
\hline & & DIP $^{0 /-}$ & $\mathbf{D I P}^{0 /-}$ & Sq/cat & $\mathbf{R u} \mathbf{u}^{\mathrm{II} / \mathrm{III}}$ \\
\hline Ru-sq* & $\begin{array}{c}\mathrm{E}_{1 / 2}{ }^{\mathrm{a}}[\mathrm{V}] \\
(\mathrm{RDE})\end{array}$ & $-1.876 \pm 0.039$ & $-1.578 \pm 0.035$ & $-0.249 \pm 0.010$ & $0.647 \pm 0.018$ \\
\hline 1 & $\begin{array}{c}\mathrm{E}_{1 / 2}^{\mathrm{a}}[\mathrm{V}] \\
(\mathrm{RDE})\end{array}$ & $-1.848 \pm 0.015$ & $-1.537 \pm 0.008$ & $-0.284 \pm 0.005$ & $0.595 \pm 0.011$ \\
\hline 2 & $\begin{array}{c}\mathbf{E}_{1 / 2}{ }^{\mathrm{a}}[\mathrm{V}] \\
\text { (RDE) }\end{array}$ & $-1.833 \pm 0.007$ & $-1.497 \pm 0.012$ & $-0.252 \pm 0.011$ & $0.615 \pm 0.003$ \\
\hline 3 & $\begin{array}{c}\mathbf{E}_{1 / 2}{ }^{\mathrm{a}}[\mathrm{V}] \\
(\mathrm{RDE})\end{array}$ & $-1.836 \pm 0.028$ & $-1.472 \pm 0.070$ & $-0.265 \pm 0.019$ & $0.636 \pm 0.011$ \\
\hline 4 & $\begin{array}{c}\mathrm{E}_{1 / 2}{ }^{\mathrm{a}}[\mathrm{V}] \\
(\mathrm{RDE})\end{array}$ & $-1.839 \pm 0.017$ & $-1.515 \pm 0.005$ & $-0.271 \pm 0.008$ & $0.574 \pm 0.001$ \\
\hline
\end{tabular}

"Values taken from $\left[{ }^{29}\right]$ We however note that these experiments were performed on the same days. ${ }^{\text {a }} \mathrm{E}_{1 / 2}=$ half-wave.

While compounds 1-4 are easily oxidized by air, their reduction to the respective neutral forms within the cell is also feasible. The glutathione system (GSSG/2GSH redox couple) is the most abundant redox couple in a cell and therefore was selected for this experiment. ${ }^{48}$ Nearly full conversion of 1 to its neutral form could be achieved using 5 equivalents of glutathione in a 1:1 mixture of DMF and water containing $20 \mathrm{mM}$ of $\mathrm{NaHCO}_{3}$ at $40^{\circ} \mathrm{C}$, strongly suggesting that compounds $1-4$ can at least be partially reduced to their neutral form inside the cell (see Figure S5). Slightly alkaline conditions were thereby necessary in these experiments, most likely to either lower the oxidation potential of the thiol functional group on the cysteine building block through deprotonation or to prevent the formation of $\mathrm{HPF}_{6}$ (note that in a biological setting basic 
amino acids or common intracellular buffers can easily serve this function). In addition, these measurements underline the charge-transfer nature of all transitions in the Vis/NIR region as all corresponding absorptions experience a blue-shift with an increase in solvent polarity; i.e., these complexes display negative solvatochromism.

Remarkably, the presence of one or more EWGs on the dioxo ligand causes a distinct change in the electronic structure of the complex. The CV and RDE voltammograms of $\mathbf{5}$ are shown in Figure 6a, while the voltammograms of compound $\mathbf{6}$ are available in the SI (Figure S4). The voltammograms of 5 were recorded over two distinct potential ranges, from $-1.0 \mathrm{~V}$ to $-2.0 \mathrm{~V}$ and from $-1.0 \mathrm{~V}$ to $1.0 \mathrm{~V}$ to avoid the adsorption of the complex on the electrode (Figure S4).

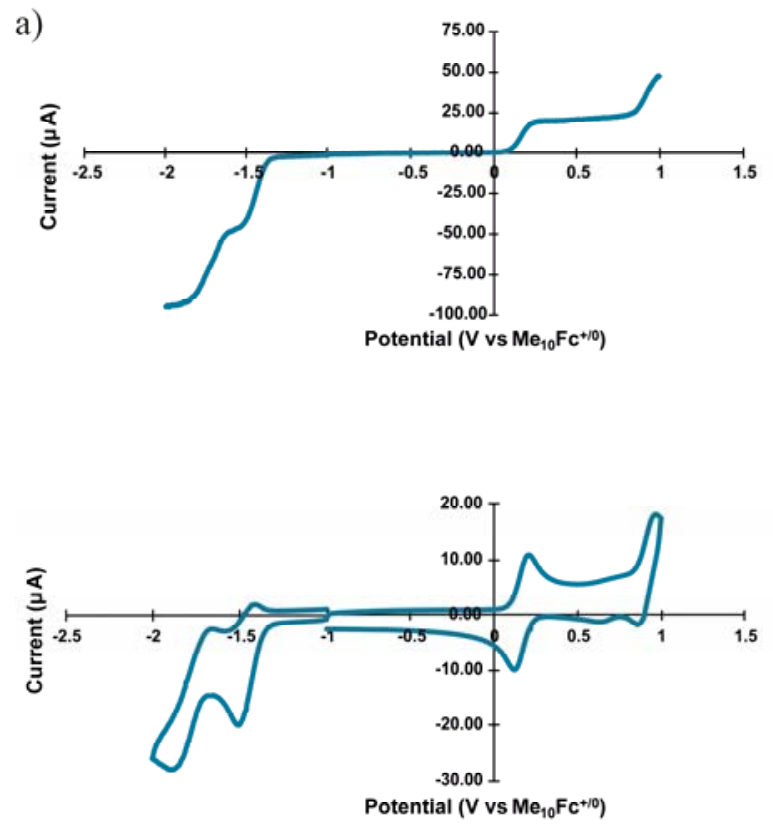

b)

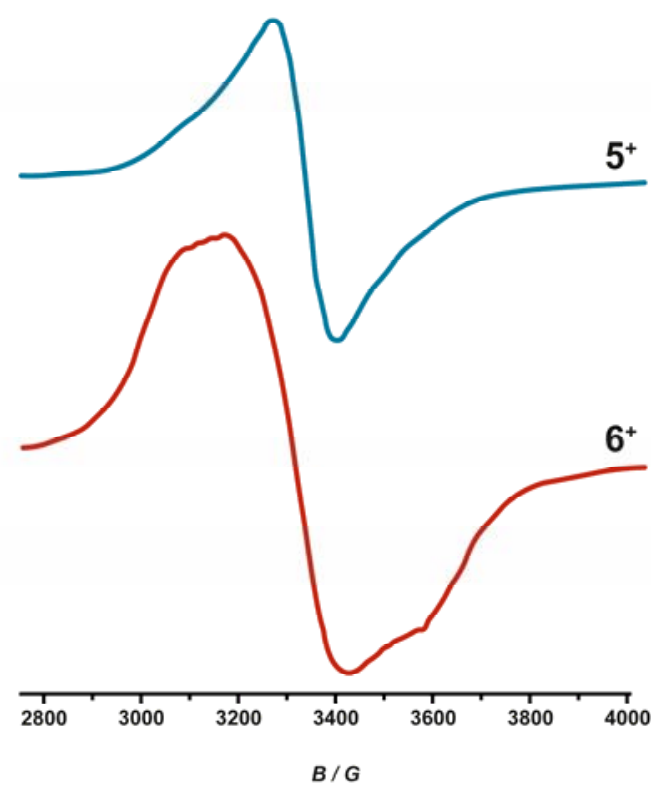

Figure 6. (a) RDE and cyclic voltammograms of complex 5 (from -2.0 to $-1.0 \mathrm{~V}$ and from -1.0 to $+1.0 \mathrm{~V})$ at a glassy carbon electrode in DMF $(1 \mathrm{mM})$ containing $\mathrm{NBu}_{4} \mathrm{PF}_{6}$ $(100 \mathrm{mM})$ as supporting electrolyte. Data were recorded versus SCE at scan rate of 100 $\mathrm{mV} / \mathrm{s}$ and recalculated versus $\mathrm{Me}_{10} \mathrm{Fc}^{0 /+}$ potential value $(-0.001 \mathrm{~V}$ and $-0.002 \mathrm{~V}$ for $\mathrm{RDE}$ and CV respectively). (b) EPR spectra of complexes $50 x$ and $60 x$ at $-140{ }^{\circ} \mathrm{C}$. 
Complexes 5, 6 are EPR silent from $20^{\circ} \mathrm{C}$ down to $-150{ }^{\circ} \mathrm{C}$ which confirms that the dioxo ligand is present in its catecholate form as found by UV/Vis/NIR spectroscopy and the elemental analysis. To provide an attribution of the observed voltammetric features in the positive potential range, further EPR experiments were conducted on the monooxidized forms of 5 and $\mathbf{6}$ (50x and 6ox, respectively, in Scheme 2). Complexes 5 and $\mathbf{6}$ were converted to their monocationc forms by treatment with an excess of ferrocenium hexafluorophosphate $\left(\mathrm{FcHPF}_{6}, E_{1 / 2}=0.450 \mathrm{~V}\right.$ vs SCE in DMF/0.1 M $\left.\mathrm{NBu}_{4} \mathrm{PF}_{6}\right) .{ }^{49}$

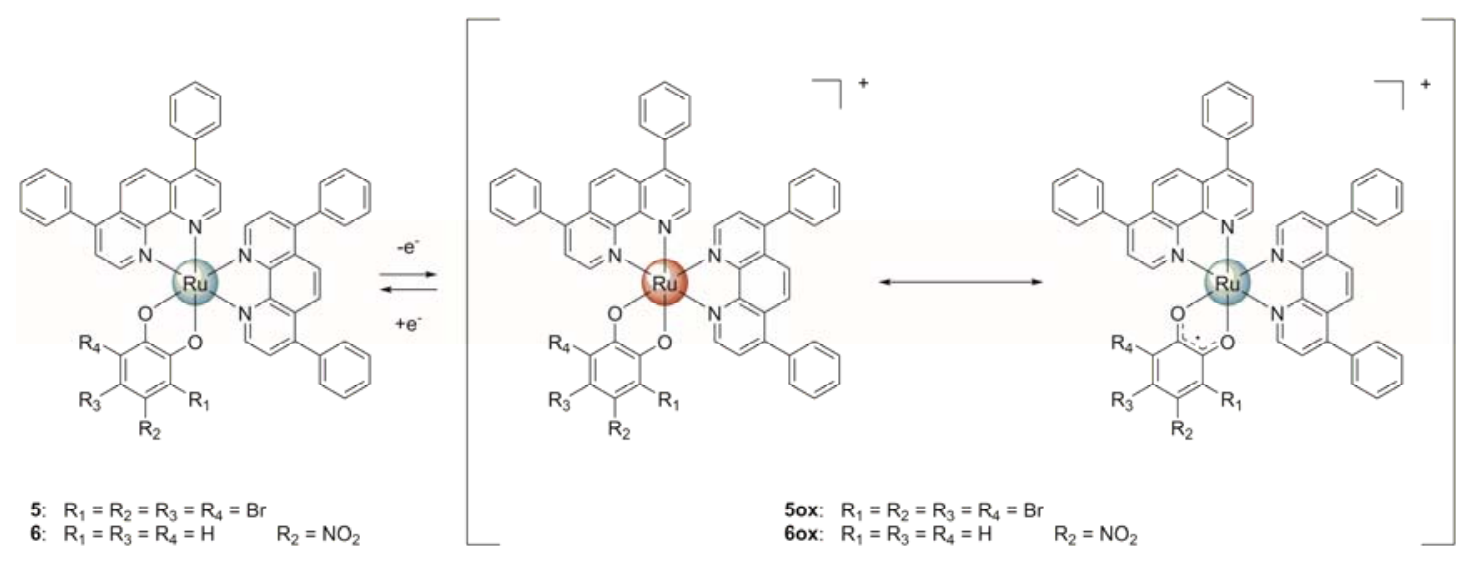

Scheme 2. Structures of 5, 6 and 5ox, 6ox represented as two resonance structures. Ru oxidation states + II and + III are marked in green and red respectively.

5ox and 6ox are EPR active, giving slightly anisotropic signals at $-140{ }^{\circ} \mathrm{C}$ with a $g_{\text {av }}$ of 2.019 for $50 x$ and of 2.032 for $60 x$ (Figure 4 and 6b). The absence of an EPR signal at room temperature for the oxidized complexes is explained by the electron-poor nature of the per-brominated- and nitro-substituted ligands, which increases the contribution of the Ru center to the spin density in the case of the oxidized complexes at the expense of the dioxo ligand. ${ }^{50}$ Indeed, as reported in Table 1 , the spin density on the Ru center increases to $0.4|\mathrm{e}-|$ in the case of $\mathbf{5 0 x}$ and $\mathbf{6 0 x}$ with a corresponding spin density on the 
dioxo ligand of roughly $0.6|\mathrm{e}-|$. Therefore, 5ox and $\mathbf{6 0 x}$ have their spin density nearly equally shared between the $\mathrm{Ru}$ ion and the dioxo ligand, corresponding to a strong orbital mixing. This can be represented as the two resonance structures of Scheme 2, where the contribution of the $\mathrm{Ru}(\mathrm{III}) / \mathrm{cat}$ form is nearly as important as the $\mathrm{Ru}(\mathrm{II}) / \mathrm{sq}$ one. A higher metal contribution to the overall spin densities is also indicated by distinct anisotropy of the g-tensor, which is more clearly evident for 6ox (i.e., showing the larger computed spin density) with individual g-tensor components of $g_{x}=1.870, g_{y}=$ $2.025, \mathrm{~g}_{\mathrm{z}}=2.190$ as determined by simulation of the experimental spectrum (see Figure $\mathrm{S} 3$ of the SI). Table 3 and S4 list the potentials related to the redox processes observed for compounds $\mathbf{5 ,} \mathbf{6}$.

Table 3. Electrochemical data for complexes 5 and $\mathbf{6}$.

\begin{tabular}{|c|c|c|c|c|c|}
\hline & & Ph2 $_{2}$ Phen $^{0 /-}$ & Ph$_{2}$ Phen $^{0 /-}$ & Ox1 & Ox2 \\
\hline 5 & $\begin{array}{c}\mathbf{E}_{1 / 2}{ }^{\mathrm{a}}[\mathrm{V}] \\
(\mathrm{RDE})\end{array}$ & $-1.746 \pm 0.003$ & $-1.423 \pm 0.002$ & $0.182 \pm 0.005$ & $0.927 \pm 0.008$ \\
\hline 6 & $\begin{array}{c}\mathbf{E}_{1 / 2}{ }^{\mathbf{a}}[\mathrm{V}] \\
(\mathrm{RDE})\end{array}$ & $-1.737 \pm 0.009$ & $-1.440 \pm 0.009$ & $0.164 \pm 0.013$ & $0.970 \pm 0.009$ \\
\hline
\end{tabular}

${ }^{\mathrm{a}} \mathrm{E}_{1 / 2}=$ half-wave.

To shed additional light on the impact of the substituent on the dioxo ligand, complex 5 was also subjected to UV/Vis/NIR spectroelectrochemical investigations in the positive potential range. As evident from Figure 7a, the generation of the monocation furnishes a structured, broad band with a maximum at $940 \mathrm{~nm}$, while the features, characteristic to the neutral forms disappear. The significant red-shift of this band as compared to compounds $\mathbf{1 - 4}$ is a clear token of the electron poor nature of the corresponding semiquinonate ligand, which lowers the energy difference between the $\mathrm{Ru}(\mathrm{II})$ donor and the dioxo ligand acceptor orbitals. The relatively larger loss of 
electron density experienced by the ruthenium atom and the rather electron-poor nature of the electrogenerated semiquinonate ligands in oxidized 5ox are further underlined by the blue shift of the $\mathrm{Ru} \rightarrow$ DIP MLCT and sq $\rightarrow$ DIP LL'CT bands in the visible range to 465 and $410 \mathrm{~nm}$ instead of 510 and $470 \mathrm{~nm}$ observed for $\mathbf{1}$. Further oxidation to the dication, in agreement with the CV studies, leads to decomposition as rereduction after electrolysis yielded spectra that considerably differed to those of their monocationic or neutral forms (see Figure 7b).

a)

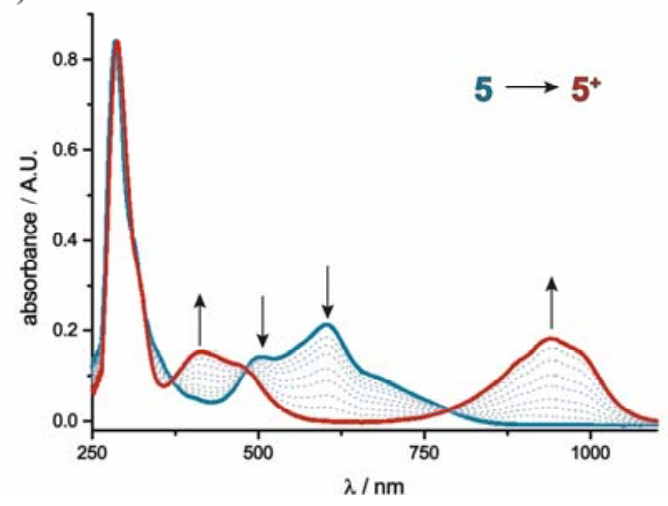

b)

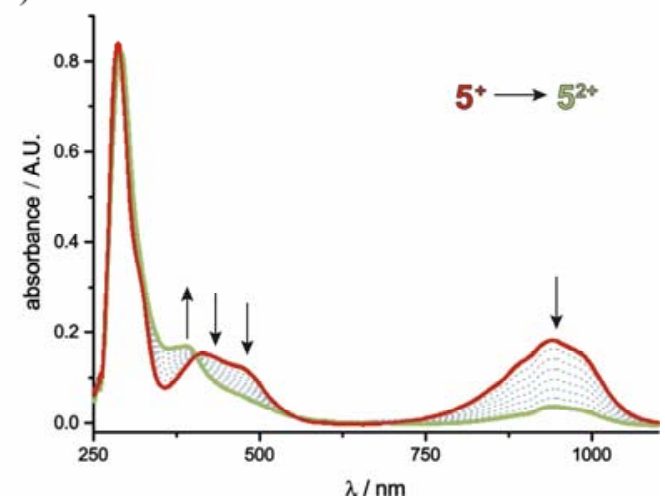

Figure 7. UV/Vis/NIR-spectroelectrochemistry data for complex 5.

The change from an EDG to an EWG at the sq/cat ligand has therefore two effects. First, the overall redox potential of the molecule is increased in such a manner that, applying the same synthetic procedure and under identical conditions, no longer a paramagnetic, cationic but a neutral, diamagnetic complex is obtained. Secondly, the spin density in the monocationic form presents distinctly larger contributions from the ruthenium center when EWG are present. This occurrence results in a slight increase in EPR signal anisotropy and, more importantly, the absence of a room temperature EPR signal in 5ox and 6ox.

\section{Stability in DMSO and human plasma}


Next, the stability of compounds 1-6 was investigated in DMSO and in human plasma. DMSO stability is a key factor to consider in medicinal chemistry as this solvent, in some cases, was found to be problematic for biological experiments for its coordinative property. ${ }^{51-53}$ The stability in DMSO was monitored by ${ }^{1} \mathrm{H}$ NMR spectroscopy over 96 $\mathrm{h}$ at room temperature. Overall, all complexes are stable under these conditions as no significant new peaks appear in the spectra (Figure S6). Only complex $\mathbf{3}$ shows a certain degree of degradation after $96 \mathrm{~h}$, displaying a conversion of about $15 \%$ of the initial complex. The spectrum of complex 3 shows new, more resolved peaks which are a clear indication of the formation of a non-paramagnetic product. Additionally, for estimating the stability under the physiological conditions, the stability of complex 1 (the most promising of the series) was investigated in human plasma. Complex 1 was incubated over $96 \mathrm{~h}$ in human plasma at $37{ }^{\circ} \mathrm{C}$ in the presence of an internal standard (caffeine). Figure S7 reveals a linear decrease of concentration of complex 1 over time and a half-life of $48 \mathrm{~h}$.

\section{Cytotoxicity Studies}

The first step toward the biological investigation of complexes 1-6 was the evaluation of cell viability in monolayer cultures of HeLa (human cervical adenocarcinoma), A2780 (human ovarian carcinoma), A2780 cis (human cisplatin resistant ovarian carcinoma), A2780 ADR (human doxorubicin resistant ovarian carcinoma), CT-26 (mouse colon adenocarcinoma), CT-26 LUC (mouse colon adenocarcinoma stably expressing luciferase) and RPE-1 (human normal retina pigmented epithelial) cell lines using a fluorometric cell viability assay (single graphs available in Figures S8). ${ }^{54}$ Doxorubicin and cisplatin, as well as the ligands and the $\mathbf{R u}(\mathbf{D I P})_{2} \mathbf{C l}_{2}$ precursor were tested in the same cell lines as positive and additional controls (Table 4 and Table S5) ${ }^{55,56}$ Table 4 displays the $\mathrm{IC}_{50}$ (the half maximal inhibitory concentration) values of 
the tested compounds and the previously reported $\mathbf{R u}$-sq. ${ }^{29} \mathbf{R u}-\mathbf{s q}$ is the analogous complex carrying the unsubstituted semiquinonate ligand. The comparison between Ru-sq and the derivatives carrying an EDG and EWG substituted dioxo ligand (compounds 1-4 and 5, 6, respectively) reveals how the electron density on the organic moiety impacts the observed cytotoxicity in the tested cell lines. In general, compounds 1-4 present higher cytotoxicity in most of the cell lines tested. In contrast, complexes 5 and $\mathbf{6}$ show much lower cytotoxicity with $\mathrm{IC}_{50}$ in the micromolar range for all the cell lines tested. Of particular interest is complex $\mathbf{1}$ with an $\mathrm{IC}_{50}$ in the low nanomolar range $(0.07 \mu \mathrm{M})$ against the cisplatin resistant cell line which makes it 10 times more active than doxorubicin and around 200 times more active than cisplatin $(0.54 \mu \mathrm{M}$ and 18.33 $\mu \mathrm{M}$ for doxorubicin and cisplatin, respectively). Complex 1 presents an $\mathrm{IC}_{50}$ of $0.7 \mu \mathrm{M}$ against the doxorubicin resistant cell line, which is 10 times lower than the values for Ru-sq and cisplatin $(4.13 \mu \mathrm{M}$ and $8.32 \mu \mathrm{M}$ for $\mathbf{R u}-\mathbf{s q}$ and cisplatin, respectively). Overall, complexes 1-4 display a cytotoxicity which is comparable to that of doxorubicin and much higher than that of cisplatin. The $\mathbf{R u}(\mathbf{D I P})_{\mathbf{2}} \mathbf{C l}_{\mathbf{2}}$ precursor (Table 4) and the different catechols (Table S4), display a much lower activity suggesting that the great activity shown by complexes $\mathbf{1 - 4}$ is the consequence of the coordination of electron rich sq ligands to the $\mathrm{Ru}(\mathrm{II})$ polypyridyl core.

Table 4. IC 50 values for $\mathbf{1 - 6}$, Ru-sq, cisplatin, doxorubicin and $\mathbf{R u}(\mathbf{D I P})_{2} \mathbf{C l}_{2}$ on different cell lines.

\begin{tabular}{|c|c|c|c|c|c|c|c|}
\hline $\mathrm{IC}_{50}(\mu \mathrm{M})$ & $\mathrm{HeLa}$ & A2780 & $\begin{array}{c}\text { A2780 } \\
\text { ADR }\end{array}$ & A2780 cis & CT-26 & $\begin{array}{l}\text { CT-26 } \\
\text { LUC }\end{array}$ & RPE-1 \\
\hline Cisplatin* & $\begin{array}{c}9.28 \pm \\
0.20\end{array}$ & $\begin{array}{c}4.00 \pm \\
0.76\end{array}$ & $\begin{array}{c}8.32 \pm \\
0.71\end{array}$ & $\begin{array}{c}18.33 \pm \\
2.92\end{array}$ & $\begin{array}{c}2.60 \pm \\
0.18\end{array}$ & $\begin{array}{c}2.42 \pm \\
0.23\end{array}$ & $\begin{array}{c}30.24 \pm \\
5.11\end{array}$ \\
\hline Doxorubicin* & $\begin{array}{c}0.34 \pm \\
0.02\end{array}$ & $\begin{array}{c}0.19 \pm \\
0.03\end{array}$ & $\begin{array}{c}5.94 \pm \\
0.58\end{array}$ & $\begin{array}{c}0.54 \pm \\
0.04\end{array}$ & $\begin{array}{c}0.082 \pm \\
0.003\end{array}$ & $\begin{array}{c}0.18 \pm \\
0.006\end{array}$ & $\begin{array}{c}0.89 \pm \\
0.17\end{array}$ \\
\hline $\mathrm{Ru}(\mathrm{DIP})_{2} \mathrm{Cl}_{2}{ }^{*}$ & $\begin{array}{c}15.03 \pm \\
0.4\end{array}$ & $\begin{array}{c}4.69 \pm \\
0.14\end{array}$ & $\begin{array}{c}78.27 \pm \\
4.9\end{array}$ & $\begin{array}{c}6.36 \pm \\
0.57\end{array}$ & $\begin{array}{c}9.20 \pm \\
1.22\end{array}$ & $6.65 \pm 0.5$ & $\begin{array}{c}3.13 \pm \\
0.07\end{array}$ \\
\hline
\end{tabular}




\begin{tabular}{|c|c|c|c|c|c|c|c|}
\hline $\mathbf{R u}-\mathbf{s q}{ }^{*}$ & $\begin{array}{c}0.50 \pm \\
0.01\end{array}$ & $\begin{array}{c}0.67 \pm \\
0.04\end{array}$ & $4.13 \pm 0.2$ & $\begin{array}{c}0.45 \pm \\
0.03\end{array}$ & $\begin{array}{c}1.00 \pm \\
0.03\end{array}$ & $\begin{array}{c}1.51 \pm \\
0.14\end{array}$ & $\begin{array}{c}0.90 \pm \\
0.04\end{array}$ \\
\hline 1 & $\begin{array}{c}0.124 \pm \\
0.004\end{array}$ & $\begin{array}{c}0.0261 \pm \\
0.0005\end{array}$ & $\begin{array}{c}0.70 \pm \\
0.05\end{array}$ & $\begin{array}{c}0.076 \pm \\
0.005\end{array}$ & $\begin{array}{c}0.067 \pm \\
0.004\end{array}$ & $\begin{array}{c}0.269 \pm \\
0.007\end{array}$ & $\begin{array}{c}0.764 \pm \\
0.23\end{array}$ \\
\hline 2 & $\begin{array}{c}0.353 \pm \\
0.006\end{array}$ & $\begin{array}{c}0.18 \pm \\
0.03\end{array}$ & $\begin{array}{c}1.05 \pm \\
0.22\end{array}$ & $\begin{array}{c}0.39 \pm \\
0.07\end{array}$ & $\begin{array}{c}0.31 \pm \\
0.02\end{array}$ & $\begin{array}{c}0.24 \pm \\
0.01\end{array}$ & $0.67 \pm 0.2$ \\
\hline 3 & $\begin{array}{c}0.61 \pm \\
0.07\end{array}$ & $\begin{array}{c}0.20 \pm \\
0.01\end{array}$ & $\begin{array}{c}1.45 \pm \\
0.14\end{array}$ & $\begin{array}{c}0.39 \pm \\
0.03\end{array}$ & $\begin{array}{c}0.65 \pm \\
0.04\end{array}$ & $\begin{array}{c}0.42 \pm \\
0.01\end{array}$ & $\begin{array}{c}0.58 \pm \\
0.01\end{array}$ \\
\hline 4 & $\begin{array}{c}2.11 \pm \\
0.12\end{array}$ & $\begin{array}{c}0.53 \pm \\
0.03\end{array}$ & $\begin{array}{c}1.91 \pm \\
0.08\end{array}$ & $\begin{array}{c}0.80 \pm \\
0.03\end{array}$ & $\begin{array}{c}1.167 \pm \\
0.15\end{array}$ & $\begin{array}{c}1.147 \pm \\
0.224\end{array}$ & $\begin{array}{c}2.965 \pm \\
0.45\end{array}$ \\
\hline 5 & $\begin{array}{c}10.46 \pm \\
0.25\end{array}$ & $\begin{array}{c}10.23 \pm \\
0.14\end{array}$ & $\begin{array}{c}15.01 \pm \\
0.75\end{array}$ & $\begin{array}{c}17.17 \pm \\
1.4\end{array}$ & $\begin{array}{c}13.49 \pm \\
0.5\end{array}$ & $\begin{array}{c}11.64 \pm \\
0.7\end{array}$ & $\begin{array}{c}23.15 \pm \\
2.5\end{array}$ \\
\hline 6 & $\begin{array}{c}10.03 \pm \\
0.44\end{array}$ & $12.4 \pm 0.8$ & $\begin{array}{c}18.63 \pm \\
2.02\end{array}$ & $\begin{array}{c}16.37 \pm \\
2.04\end{array}$ & $\begin{array}{c}7.61 \pm \\
0.11\end{array}$ & $\begin{array}{c}9.01 \pm \\
0.19\end{array}$ & $\begin{array}{c}16.55 \pm \\
0.98\end{array}$ \\
\hline
\end{tabular}

*Values taken from $\left[{ }^{29}\right]$ We however note that these experiments were performed on the same days.

Complex 1 was found to be the most promising candidate among the series of complexes investigated in the 2D model due to its remarkably high cytotoxicity and its great activity towards resistant cell lines, its cytotoxicity was explored in a MultiCellular Tumour Spheroids (MCTS) model. ${ }^{57}$ In 3D spheroids, proper cell to cell and cell to environment interactions, as well as cellular morphology and polarity is maintained. Additionally growth pattern, metabolism and gene expression mimic the complexity of initial stages of solid tumours. ${ }^{57,58}$ These features allow for a good estimation of in vivo antitumor activity, qualifying MCTS as a more reliable model than monolayer cell cultures in cancer research. ${ }^{58-60}$ In addition to the complex of interest (1), the $\mathbf{R u}(\mathbf{D I P})_{2} \mathbf{C l}_{\mathbf{2}}$ precursor, the 3-methoxycatechol ligand and positive controls (cisplatin and doxorubicin) $)^{59,60}$ were tested via a luminescent cell viability assay in HeLa MCTS (single graphs are availabe in Figure S9). Moreover, Ru-sq was tested for comparative porposes. Table 5 shows the $\mathrm{IC}_{50}$ values after a $48 \mathrm{~h}$ treatment for all the compounds tested. Complex 1 displays high cytotoxicity toward HeLa MCTS with an $\mathrm{IC}_{50} \approx 21 \mu \mathrm{M}$. This value indicates an activity which is almost the double of the current drugs cisplatin and doxorubicin ( $\mathrm{IC}_{50} \approx 46 \mu \mathrm{M}$ and $39 \mu \mathrm{M}$, respectively). Nevertheless, the previously reported $\mathbf{R u}-\mathbf{s q}$ still shows a slightly higher cytotoxicity $\left(\mathrm{IC}_{50} \approx 14 \mu \mathrm{M}\right)$. 
3-methoxycatechol proved to be nontoxic and the $\mathbf{R u}(\mathbf{D I P})_{\mathbf{2}} \mathbf{C l}_{\mathbf{2}}$ precursor showed a cytotoxicity comparable to cisplatin.

Table 5. IC50 values for complex 1, cisplatin, doxorubicin, $\mathbf{R u}(\mathbf{D I P})_{2} \mathbf{C l}_{2}$ and 3methoxycatechol in multicellular HeLa cancer cell spheroids.

\begin{tabular}{|c|c|c|c|c|c|c|}
\hline IC $_{\mathbf{5 0}}(\boldsymbol{\mu M})$ & Cisplatin $^{*}$ & $\begin{array}{c}\text { Doxorubic } \\
\text { in }^{*}\end{array}$ & $\mathbf{R u}^{*} \mathbf{s q}^{*}$ & $\mathbf{1}$ & $\begin{array}{c}\mathbf{R u}(\mathbf{D I P})_{2} \\
\mathbf{C l}_{\mathbf{2}}\end{array}$ & $\begin{array}{c}\mathbf{3}- \\
\text { Methoxyc } \\
\text { atechol }\end{array}$ \\
\hline HeLa & $46.49 \pm$ & $38.59 \pm$ & $14.11 \pm$ & $21.01 \pm$ & $59.84 \pm$ & $>100$ \\
MCTSs & 4.18 & 0.43 & 0.09 & 0.66 & $3.05^{*}$ & \\
\hline
\end{tabular}

"Values taken from $\left[{ }^{29}\right]$ We however note that these experiments were performed on the same days.

To evaluate the time dependent effect on the growth of MCTS treated with complex $\mathbf{1}$, an additional experiment was performed. $400 \mu \mathrm{m}$ HeLa MCTS were treated with a range of different concentrations of $\mathbf{1}$. Every three days, half of the media in the wells was exchanged (treatment concentration consequently decreased by half) and pictures of the spheroids were taken (Figure 8a). HeLa MCTS had reduced diameter when treated with concentrations higher than the $\operatorname{IC}_{50}(20,25$ and $30 \mu \mathrm{M})$ of complex 1 . Additionally, Figure 8 indicates that this effect was maintained even after 13 days for the highest concentration, while, a slow regrowth was observed for 20 and $25 \mu \mathrm{M}$ treatment. These findings are similar to the one previously reported for Ru-sq complex. $^{29}$ 
a)

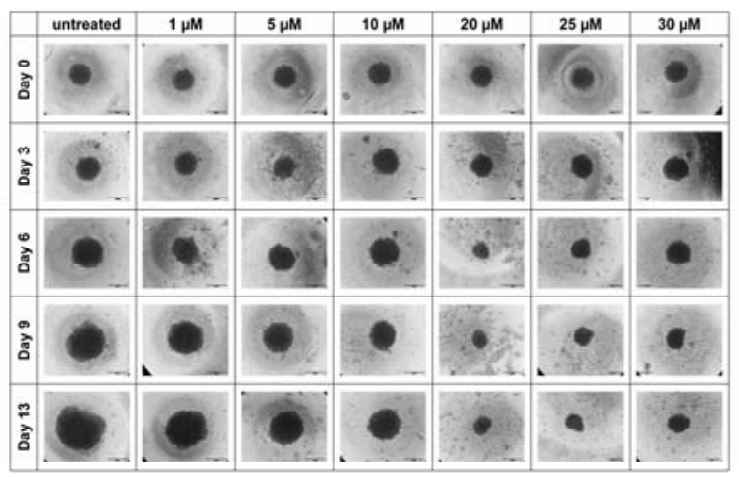

b)

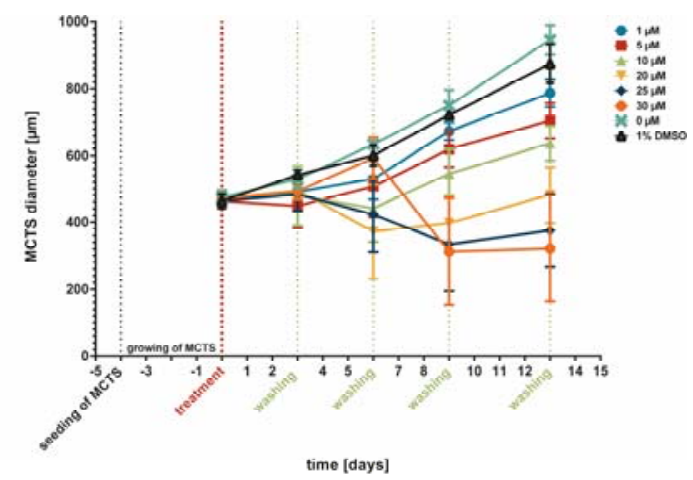

Figure 8. Changes in growth kinetics of MCTSs treated with complex 1 at different concentrations $(1,5,10,20,25$ and $30 \mu \mathrm{M})$. (a) Images collected at day 0 (before treatment) and at day 3, 6, 9 and 13. b) MCTSs diameter measured at different time points. Blue dotted line indicates day of seeding, red dashed line indicates day of treatment, green dotted lines indicate days of washing.

Overall, the outstanding activites shown by complex $\mathbf{1}$ in the monolayer cells model is confirmed by a MCTSs model. These findings represent a powerful encouragement to the further investigation of complexes $\mathbf{1}$ as potential chemotherapeutic agents.

\section{Cell Death Mechanism.}

Many of the novel or existing chemotherapeutic agents are developed to trigger cell death through apoptosis. ${ }^{63}$ This is considered a carefully regulated and energy dependend type of cell death in contrast to necrosis considered a rapid, unregulated, energy- independent mode of death. ${ }^{64}$ The mode of cell death induced by the treatment with complex 1 was investigated in HeLa cell line via flow cytometry using Annexin V and propidium iodide (PI) staining method. Figure 9a shows the obtained dot-plots at $\mathrm{t}=24 \mathrm{~h}$ (see Figure $\mathrm{S} 10$ for the dot plots at each time point). Figure $9 \mathrm{~b}$ represents the percentage of cell population in different stages of cell death, at different time points in 
comparison to staurosporin (apoptosis inducer, positive control). ${ }^{72}$ Collected data demonstrated that after $24 \mathrm{~h}$ treatment, a large population of HeLa cells was in the late apoptotic/necrotic stage. It is worth noting that apoptosis or necrosis are induced by different pathways and mechanisms, and it is highly unlikely for a cell to undergo necrotic death after several hours of early apoptotic stage. Hence, these data indicate that complex $\mathbf{1}$ is most probably inducing cell death through apoptosis.

a)

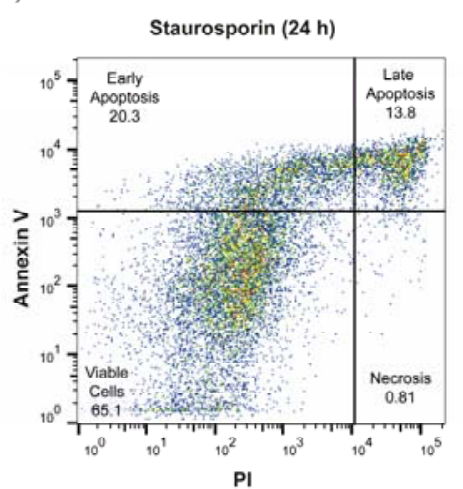

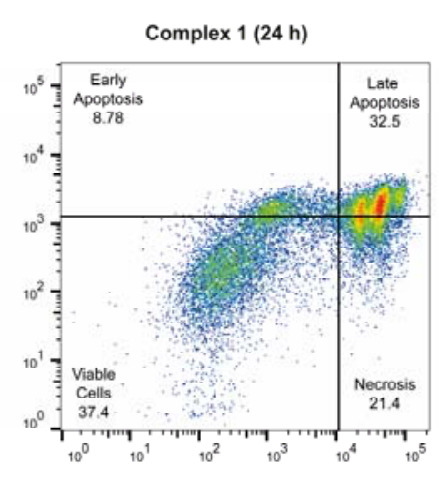

b)

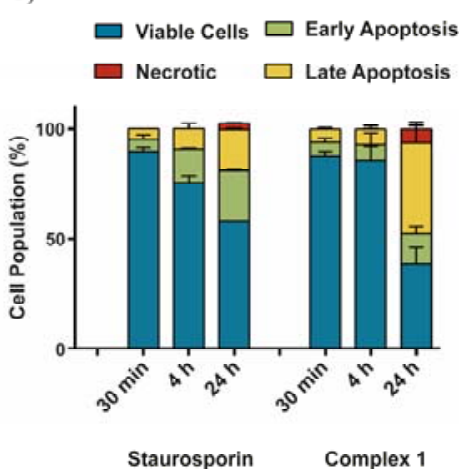

Figure 9. a) Flow cytometry dot-plots of Annexin V and PI staining in HeLa cells treated with complex $1(10 \mu \mathrm{M})$ and staurosporine $(1 \mu \mathrm{M})$ at $24 \mathrm{~h}$. b) Percentage of cell population in different stages of cell death for staurosporin (positive control) and complex

\section{Cellular Uptake, Biodistribution, and DNA Metalation.}

The high cytotoxicity of complex $\mathbf{1}$ in the tested cell lines encouraged its further biological studies. Firstly, cellular uptake, mechanism of uptake and intracellular distribution were tested using Inductively Coupled Plasma Mass Spectrometry (ICPMS). Working concentrations and incubation times were chosen accordingly to avoid extended cell mass loss due to the high cytotoxicity of the complexes but considering a final ruthenium amount that allowed for the determination of the metal content. Nevertheless, the working conditions $(5 \mu \mathrm{M}$ treatment for $2 \mathrm{~h})$ allowed for a minor accumulation of the drug cisplatin, which was used as control. ${ }^{65,6667}$ Complex 1 shows 
higher cellular accumulation than the positive control cisplatin and the $\mathbf{R u} \mathbf{u} \mathbf{s q}$ analogue previously reported, ${ }^{29}$ (Figure 10a). To clarify whether the mechanism of uptake involves passive or active mechanisms additional experiments were performed. HeLa cells were kept at low temperature $\left(4^{\circ} \mathrm{C}\right)$ or were pre-treated with different uptake pathways inhibitors. Thus, 2-deoxy-D-glucose and oligomycin were used to block cellular metabolism, chloroquine or ammonium chloride were used to impede endocytic pathways, and tetraethylammonium chloride was used to block cation transporters. After pre-treatment, cells were incubated with the test compounds $(2 \mathrm{~h}, 5$ $\mu \mathrm{M})$. The amounts of ruthenium found in cells were then quantified using ICP-MS. Low temperature slightly inhibited the uptake of complex 1 while all the other conditions (regulating active transportation mechanisms) did not affect the total uptake (Figure S11). These findings strongly suggest that the internalisation of complex $\mathbf{1}$ is due only to a passive, energy independent mechanism, unlike Ru-sq, whose mechanism of uptake involves both active and passive transports. ${ }^{29}$ Intracellular distribution among cytoplasm, mitochondria, nucleus and mitochondria was determined by isolating pure cellular compartments. Most of the compounds accumulates in nucleus and lysosomes and in a smaller extent to mitochondria and cytoplasm (Figure 10b). To verify whether the accumulation in the nucleus lead to direct interaction with DNA, the genetic material was extracted from treated cells and the metal content analysed via ICP-MS. Figure 10c shows that complex 1 successfully binds DNA in a much higher extent when compared to cisplatin, which results are in perfect agreement with what previously reported. ${ }^{67}$ Even though the accumulation in the nucleus is lower, the DNA metalation shows comparable results for complex $\mathbf{1}$ and Ru-sq, which can be explained by the overall higher uptake of complex 1. 
a)

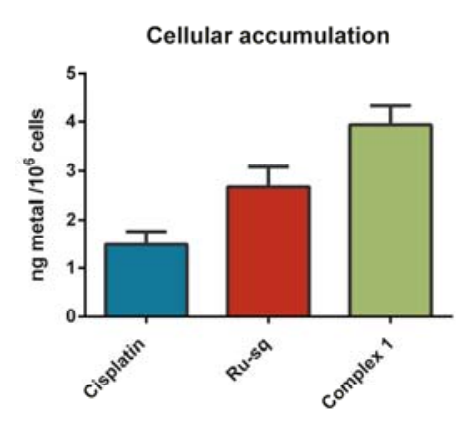

b)

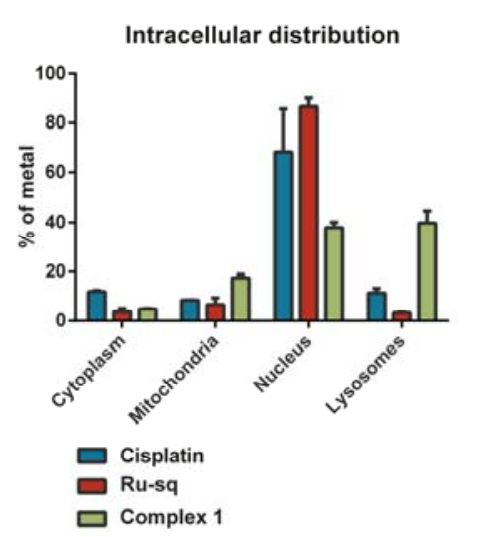

c)

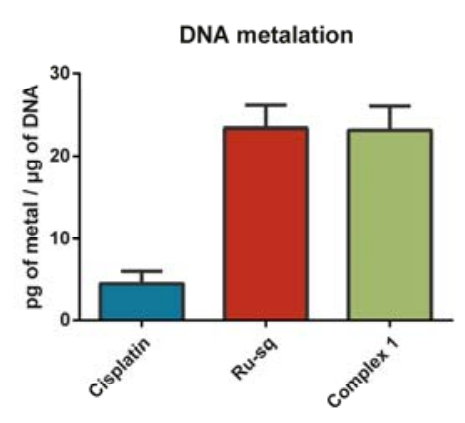

Figure 10. Cellular uptake (a), cellular fractionation (b) and DNA metalation (c) of HeLa cells after treatment with tested compounds $(5 \mu \mathrm{M}, 2 \mathrm{~h})$. Data are presented as the mean \pm SD of at least 3 technical replicates. All data related to Ru-sq were previously reported by our group. ${ }^{29} \mathrm{We}$, however, note that these experiments were performed on the same days.

\section{JC-1 Mitochondrial Membrane Potential Test and Metabolic Studies.}

Next, to gain more insights into the possible mechanism of action of complex $\mathbf{1}$, its effect on mitochondria membrane potential (MMP) and metabolic pathways were determined. First, the MMP (directly correlated to mitochondrial function ${ }^{68}$ ) was studied via JC-1 staining method. JC-1 is considered the most reliable fluorescent dye to illustrate the MMP in living cells. ${ }^{69}$ It is present as an aggregate (red fluorescent) and as a monomer (green fluorescent), respectively at high and low MMP. ${ }^{69}$ The net distinction allows for an immediate analysis of the MMP. ${ }^{69}$ Figure 11a shows the red fluorescence signal observed in HeLa cells untreated (negative control) and after $24 \mathrm{~h}$ treatment with complex 1, DMSO (vehicle control) and FCCP (carbonyl cyanide 4(trifluoromethoxy)phenylhydrazone, an uncoupling agent used as positive control). ${ }^{70} \mathrm{~A}$ slight decrease in the fluorescence is observed in the cells treated with complex $\mathbf{1}$ (from $0.05 \mu \mathrm{M}$ to $0.25 \mu \mathrm{M})$ in a concentration-dependent manner. However, even at the $\mathrm{IC}_{50}$, the effect is not as prominent as the one obtained for the positive control. It is worth 
noting that ongoing apoptosis can also generate a drop in MMP. ${ }^{70}$ Taken together, these data indicate that complex $\mathbf{1}$ is slightly decreasing mitochondria membrane potential in treated cells. To have more insights into the effect of the complex 1 in the process of oxidative phospohorylation, further experiments were performed. For this purpose, Seahorse XF Analyzer was used. The performed Mito Stress Test pointed to very low basal respiration levels, inhibited ATP production and the loss of the ability to restore proton balance after FCCP treatment (Figure 11b and Figure S12). These data suggest that the mitochondria processes are defective in HeLa cells incubated with complex $\mathbf{1}$. On the contrary, the same effects were not observed during treatment with the $\mathbf{R u}(\mathbf{D I P})_{\mathbf{2}} \mathbf{C l}_{\mathbf{2}}$ precursor or the 3-methoxycatechol ligand. Furthermore, no influence of compound 1 on the cytosolic process of glycolysis was detected (Figure S13). Unfortunately, no direct impact on three main fuel pathways could be determined due to very low oxygen consumption rates (Figure S14).

Metabolic studies confirm that the effects of complex 1 on mitochondria respiration can contribute to cell death, leading to a multiple mode of actions involving at least nucleus and mitochondria as possible targets.

a)

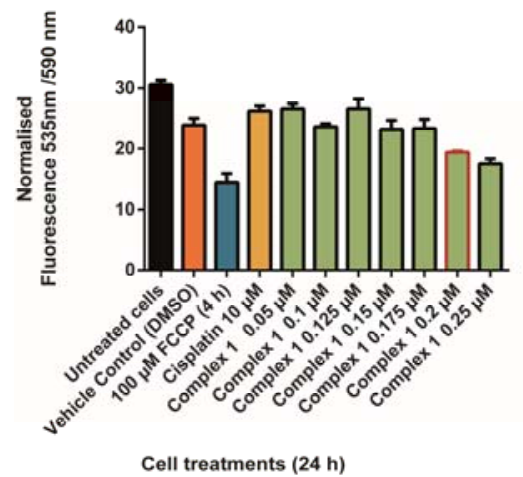

b)

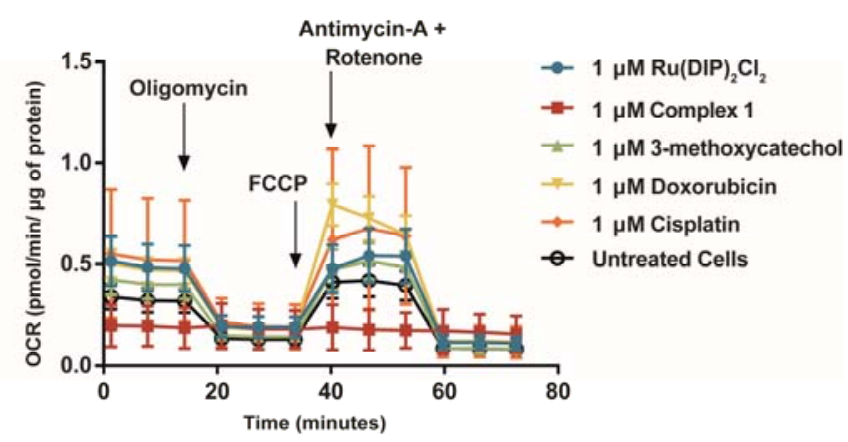

Figure 11. a) Fluorescence signal of JC-1 dye detected in HeLa cells treated for $24 \mathrm{~h}$ with different concentrations of complex 1 (from $0.05 \mu \mathrm{M}$ to $0.25 \mu \mathrm{M}$ ). The bar marked in red indicates the $\mathrm{IC}_{50}$ concentration $(0.2 \mu \mathrm{M})$. FCCP is used as positive control, 
cisplatin and DMSO (1\%) are used as negative controls. b) Mito Stress Test profile after $24 \mathrm{~h}$ treatment; oxygen consumption rate changes after treatment with specific electron transport chain inhibitors. Oligomycin (inhibitor of ATP synthase (complex V)), FCCP (uncoupling agent), Antimycin-A (complex III inhibitor) and Rotenone (complex I inhibitor).

\section{Preliminary in vivo biodistribution studies}

In this study, complex $\mathbf{1}$ demonstrated to be of great interest as potential chemotherapeutic agent. However, one of its main drawbacks is its scarce water solubility, which could limit its potential use in vivo. The analogue Ru-sq, previously reported by our group, showed potential as anticancer drug in immunocompetent mice bearing Ehrlich tumors. ${ }^{29}$ Nevertheless, its clinical interest is limited by its poor water solubility, which prevented an intravenous administration. Anticancer drugs such as paclitaxel and docetaxel have faced the same limitation but reached the clinic. ${ }^{71,72}$ Indeed, to overcome this shortcoming, formulation strategies were used, which allowed for increased apparent aqueous solubility of the drugs and therefore their parenteral injection. ${ }^{71,72}$ Following these examples, we successfully developed a formulation of compound 1 using polysorbate 80, a nonionic surfactant generally recognized as safe and already used for docetaxel. ${ }^{73}$ Using the film rehydration method, usually applied to the preparation of polymeric surfactant micelles and liposomes, ${ }^{74,75}$ up to $0.84 \pm 0.06$ $\mathrm{mg} / \mathrm{mL}$ of compound 1 could be dissolved in $50 \mathrm{mg} / \mathrm{mL}$ of polysorbate 80 , with an encapsulation efficiency of $95 \pm 3 \%$. Liver and kidneys are the main routes by which drugs and metabolites leave the body, so the effect of complex $\mathbf{1}$ on them was evaluated. $^{76}$ Complex 1 was tested in TIB-75 (mouse, epithelial liver) and HEK 293 
(human, embryonic kidney) cell lines showing cytotoxicity in both cases (Table 6, single graph available in Figure S8).

Table 6. IC 50 values for cisplatin, complex $\mathbf{1}, \mathbf{R u}(\mathbf{D I P})_{2} \mathbf{C l}_{\mathbf{2}}$ and 3-methoxycatechol in HEK293 and TIB-75 cell lines.

\begin{tabular}{|c|c|c|c|c|}
\hline $\mathbf{I C}_{\mathbf{5 0}}(\boldsymbol{\mu M})$ & Cisplatin $^{*}$ & $\mathbf{1}$ & $\mathbf{R u}(\mathbf{D I P})_{\mathbf{2}} \mathbf{C l}_{\mathbf{2}}$ & $\begin{array}{c}\text { 3- } \\
\text { Methoxycatechol }\end{array}$ \\
\hline HEK293 & $6.60 \pm 1.49$ & $0.07 \pm 0.005$ & $5.42 \pm 0.51$ & $18.96 \pm 0.88$ \\
\hline TIB-75 & $2.83 \pm 0.08$ & $0.02 \pm 0.0001$ & $5.06 \pm 0.32$ & $19.16 \pm 1.15$ \\
\hline
\end{tabular}

These results together with the ones shown in Table 4 point out the non-selectivity of complex 1 between cancerous and non-cancerous cell lines. This shortcoming is often faced in medicinal chemistry and it could be improved by the introduction of a targeting moiety. Therefore, we decided to pursue the biodistribution study with the developed formulation to verify the ability of the drug to distribute in the organism upon administration, despite its low aqueous solubility. A preliminary biodistribution study was performed on healthy BALB/c mice after intravenous injection of the formulation at a dose of $5 \mathrm{mg} / \mathrm{kg}$ of compound 1 . After 30 minutes, 1 and 2 hours, mice were sacrificed and the ruthenium content was analyzed via ICP-MS in relevant tissues (brain, liver, kidneys, spleen, intestine, lungs and blood). Worthy of note, the formulation was well tolerated, and no sign of pain or acute toxicity was observed over the course of the experiment. 


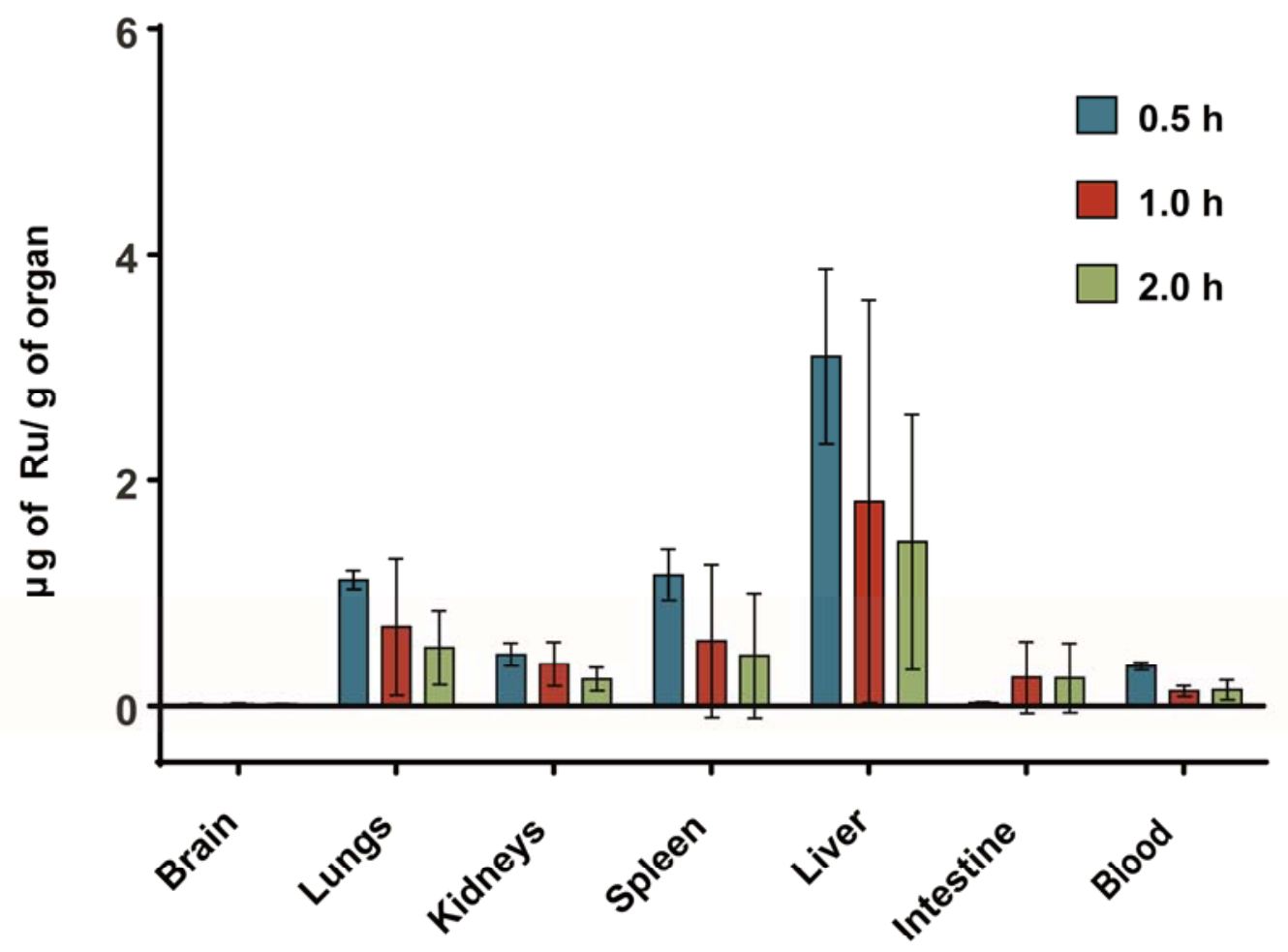

Figure 12. Biodistribution of complex $1(5 \mathrm{mg} / \mathrm{kg})$ over $2 \mathrm{~h}$ in BALB/c mice. Data are presented as the mean $\pm \mathrm{SD}$ of at least three biological replicates.

According to data shown in Figure 12, compound $\mathbf{1}$ seems to accumulate preferentially in the liver and the kidneys, and more surprisingly, in the lungs and the spleen. This phenomenon has already been described in the case of doxorubicin formulated in polysorbate 80 , and was attributed to this carrier. ${ }^{77}$ The low level of ruthenium detected in the blood at all time point suggest a fast distribution in the tissues, possibly associated to a fast renal and biliary elimination, supported by the increase of the ruthenium content in the intestine over time.

These preliminary results show compound 1's ability to distribute in the body despite its hydrophobicity using a formulation strategy. While promising, the formulation with polysorbate 80 has also been associated with side effects. ${ }^{78,79}$ To overcome this 
drawback, a more biocompatible excipient could be used, as already successfully achieved in the case of docetaxel. ${ }^{72}$ 


\section{Conclusions}

In this work, we performed a structure activity relationship study (SAR) based on the promising activity expressed by the complex Ru-sq recently reported by our group. More specifically, we explored the coordination of differently substituted catechol-type dioxo ligands to the $\mathrm{Ru}(\mathrm{DIP})_{2}$ core. Electrochemical, EPR and electronic structure studies allowed us to conclude that the two classes of dioxo ligands tested, carrying either electron-donating (EDG) or electron-withdrawing (EWG) groups, gave $\mathrm{Ru}(\mathrm{II})$ complexes with either the semiquinonate (sq, for EDG-modified dioxo ligands in complexes 1-4) or catecholate ligand (cat, for EWG-modifed dioxo ligands in complexes 5, 6). Complexes 1-4 are deep red solids and carry an overall positive charge due to the monoanionic sq ligand. Complexes $\mathbf{5}$ and $\mathbf{6}$ are blue/violet in color and overall neutral due to the dianionic charge associated with the catecholate. Both classes of complexes were found to be stable in DMSO and complex 1 displayed a half-life of $48 \mathrm{~h}$ in human plasma. Cytotoxicity studies using the monolayer model revealed that complexes 1-4 displayed much higher bioactivities than complexes 5 and $\mathbf{6}$. These findings clearly suggest that the high cytotoxicity observed is a direct consequence of the coordination of electron rich semiquinonate ligands to the $\mathrm{Ru}(\mathrm{II})$ polypyridyl core. Precisely, complex 1 was found to be the most promising candidate of this series with $\mathrm{IC}_{50}$ values in the low nanomolar range and was chosen for more detailed investigations. Firstly, its cytotoxicity was confirmed using a more reliable 3D model (MCTS), where it displayed an $\mathrm{IC}_{50}$ value of almost half of that of cisplatin and doxorubicin. Complex 1 was found to be taken up by HeLa cells very efficiently through a passive transportation mechanism. Cellular fractionation studies revealed major accumulation in the nucleus, lysosomes and in a smaller extent in the mitochondria and cytoplasm. DNA ruthenation, MMP determination and mitochondria 
metabolism studies indicated that DNA and mitochondria are both cellular targets of complex 1. Multiple targets are essential to overcome resistance, which is one of the main drawbacks associated with chemotherapy treatments nowadays. Moreover, despite poor water solubility, complex $\mathbf{1}$ demonstrated to distribute well in vivo with the use of an appropriate formulation. These results together with the advantageous modes of action and the outstanding cytotoxicity displayed by complex 1 makes it an interesting compound for clinical application in the search of potential chemotherapeutic agents against cancer. 


\section{Experimental Section}

\section{Materials}

All chemicals were either of reagent or analytical grade and used as purchased from commercial sources without additional purification. Ruthenium trichloride hydrate was provided by $\mathrm{I}^{2} \mathrm{CNS}$, 4,7-Diphenyl-1,10-phenanthroline, Lithium chloride (anhydrous, 99\%), 3-Methoxycatechol, 4-Methylcatechol, 4-tert-Butylcatechol and 4-Nitrocatechol by Alfa Aesar, 3-Methylcatechol and tetrabutylammonium hexafluorophosphate by Sigma-Aldrich, tetrabromocatechol from BOC Science. All solvents were purchased of analytical, or HPLC grade. When necessary, solvents were degassed by purging with dry, oxygen-free nitrogen for at least $30 \mathrm{~min}$ before use.

\section{Instrumentation and methods}

Amber glass or clear glassware wrapped in tin foil were used when protection from the light was necessary. Schlenk glassware and a vacuum line were employed when reactions sensitive to moisture/oxygen had to be performed under nitrogen atmosphere. Thin layer chromatography (TLC) was performed using silica gel 60 F-254 (Merck) plates with detection of spots being achieved by exposure to UV light. Column chromatography was done using Silica gel 60-200 $\mu \mathrm{m}$ (VWR). Eluent mixtures are expressed as volume to volume (v/v) ratios. ${ }^{1} \mathrm{H}$ and ${ }^{13} \mathrm{C}$ NMR spectra were measured on Bruker Avance III HD $400 \mathrm{MHz}$ or Bruker Avance Neo $500 \mathrm{MHz}$ spectrometers using the signal of the deuterated solvent as an internal standard ${ }^{80}$ The chemical shifts $\delta$ are reported in ppm (parts per million) relative to tetramethylsilane (TMS) or signals from the residual protons of deuterated solvents. Coupling constants $J$ are given in Hertz (Hz). The abbreviation for the peaks multiplicity is br (broad). ESI experiments were carried out using a 6470 Triple Quad (Agilent Technologies). Elemental analysis was performed at Science Centre, London Metropolitan University using Thermo 
Fisher (Carlo Erba) Flash 2000 Elemental Analyser, configured for \%CHN. IR spectra were recorded with SpectrumTwo FTIR Spectrometer (Perkin-Elmer) equipped with a Specac Golden GateTM ATR (attenuated total reflection) accessory; applied as neat samples; $1 / \lambda$ in $\mathrm{cm}^{-1}$. Analytical HPLC measurement was performed using the following system: 2 x Agilent G1361 1260 Prep Pump system with Agilent G7115A 1260 DAD WR Detector equipped with an Agilent Pursuit XRs 5C18 (100Å, C18 5 $\mu \mathrm{m} 250 \times 4.6 \mathrm{~mm}$ ) Column and an Agilent G1364B 1260-FC fraction collector. The solvents (HPLC grade) were acetonitrile ( $0.1 \%$ TFA, solvent A) and millipore water $(0.1 \% \mathrm{TFA}$, solvent B). The flow rate was $1 \mathrm{~mL} / \mathrm{min}$. Detection was performed at $215 \mathrm{~nm}, 250 \mathrm{~nm}, 350 \mathrm{~nm}, 450 \mathrm{~nm}, 550 \mathrm{~nm}$ and $650 \mathrm{~nm}$ with a slit of $4 \mathrm{~nm}$.

\section{Synthesis and characterization}

$\mathbf{R u}(\mathrm{DMSO})_{2} \mathbf{C l}_{2}$. $\mathrm{Ru}(\mathrm{DMSO})_{2} \mathrm{Cl}_{2}$ was synthesised following an adapted literature procedure. ${ }^{44}$ Spectroscopic data $\left({ }^{1} \mathrm{H}\right.$ NMR) are in agreement with literature. ${ }^{44}$

$\mathbf{R u}(\mathbf{D I P})_{2} \mathbf{C l}_{2}$. The complex was synthesised following an adapted literature procedure. ${ }^{45} \mathrm{~A}$ mixture of $\mathrm{Ru}(\mathrm{DMSO}){ }_{2} \mathrm{Cl}_{2}(3.0 \mathrm{~g}, 6.19 \mathrm{mmol})$, 4,7-diphenyl-1,10phenanthroline (4.11 g, $12.38 \mathrm{mmol})$ and $\mathrm{LiCl}(2.0 \mathrm{~g}, 47.18 \mathrm{mmol})$ dissolved in DMF $(100 \mathrm{~mL})$ was refluxed for $24 \mathrm{~h}$. After cooling to r.t., the solvent was reduced in vacuo and $350 \mathrm{~mL}$ of acetone were added. The mixture was then stored at $-20{ }^{\circ} \mathrm{C}$ overnight before filtration with a Buchner funnel and washed with acetone and $\mathrm{Et}_{2} \mathrm{O}$ to afford $\mathrm{Ru}\left(\mathrm{Ph}_{2} \mathrm{Phen}\right)_{2} \mathrm{Cl}_{2}$ as a deep purple solid (3.76 g, $\left.4.49 \mathrm{mmol}, 72 \%\right)$. Spectroscopic data $\left({ }^{1} \mathrm{H}\right.$ NMR) were in agreement with literature. ${ }^{45}$

\section{General method for the synthesis of 1-6}


$\mathrm{Ru}(\mathrm{DIP})_{2} \mathrm{Cl}_{2}(0.250 \mathrm{~g}, 0.3 \mathrm{mmol})$ and aq. $\mathrm{NaOH}(0.45 \mathrm{~mL}, 1 \mathrm{M})$ were dissolved in 2propanol $(20 \mathrm{~mL})$. The solution was degassed purging nitrogen through the solution for $15 \mathrm{~min}$ and the respective catechol $(0.07 \mathrm{~g}, 0.5 \mathrm{mmol})$ was added. The mixture was heated to reflux for $24 \mathrm{~h}$ under $\mathrm{N}_{2}$ atmosphere and protected from light. After cooling to r.t., the mixture was stirred open to air for $2 \mathrm{~h}$ while still protected from light and the solvent was removed under vacuum. The residual solid was dissolved in 2-propanol (2.5 mL) and $\mathrm{H}_{2} \mathrm{O}(20 \mathrm{~mL})$ and $\mathrm{NH}_{4} \mathrm{PF}_{6}(0.250 \mathrm{~g}, 1.5 \mathrm{mmol})$ were added. The mixture was stored in the fridge $\left(4^{\circ} \mathrm{C}\right)$ overnight. The precipitate was filtered with a Buchner funnel, washed with $\mathrm{H}_{2} \mathrm{O}(3 \times 50 \mathrm{~mL})$ and $\mathrm{Et}_{2} \mathrm{O}(3 \times 50 \mathrm{~mL})$ and collected. The solid was collected with DCM and dried under vacuum to deliver a crude product which was chromatographed on silica (DCM/MeCN 20:1 Rf: 0.3 for complexes 1-4, DCM/Et $2 \mathrm{O}$ 98:2 Rf: 0.8 for complex 5, DCM/MeOH 96:4 Rf: 0.4 for complex 6). Evaporation of the solvent under vacuum provided complexes 1-6. Each complex with $\mathrm{Et}_{2} \mathrm{O}$ or Heptane $(10 \mathrm{~mL})$ was sonicated for $10 \mathrm{~min}$ and then centrifuged. This procedure was repeated three times for each solvent. The solid was collected with DCM and dried under vacuum to yield a clean product. Finally the red solid was collected with DCM and dried under vacuum to afford a clean product.

\section{$\left[\mathrm{Ru}(\mathrm{DIP})_{2}(3-\right.$ methoxylsq)](PF 6$)(1)$}

Deep red solid (0.073 g, $0.07 \mathrm{mmol}, 23 \%)$. IR (Golden Gate, $\left.\mathrm{cm}^{-1}\right)$ : 3060w, 1620w, $1590 \mathrm{w}, 1540 \mathrm{w}, 1460 \mathrm{~m}, 1400 \mathrm{~m}, 1250 \mathrm{~m}, 1160 \mathrm{~m}, 1100 \mathrm{~m}, 1030 \mathrm{w}, 827 \mathrm{~s}, 764 \mathrm{~s}, 735 \mathrm{~m}$, 700s. ${ }^{1} \mathrm{H}$ NMR (500 MHz, $\mathrm{CD}_{2} \mathrm{Cl}_{2}$ ): $\delta / \mathrm{ppm}=8.91-8.50$ (br, $1 \mathrm{H}$, arom.), $8.43-8.08$ (br, 3H, arom.), $8.07-7.79$ (br, 7H, arom.), $7.75-7.46$ (br, 15H, arom.), $7.46-7.28$ (br, 2H, arom.), $7.28-6.93$ (br, $10 \mathrm{H}$, arom.). $\left.{ }^{13} \mathrm{C} \mathrm{NMR} \mathrm{(125} \mathrm{MHz,} \mathrm{CD}_{2} \mathrm{Cl}_{2}\right): \delta / \mathrm{ppm}=$ $149.62,146.57,143.72,140.55,137.05,136.03,133.07,132.47,131.27,130.31$, $130.07,130.00,129.59,129.56,129.33,128.97,128.80,128.57,125.67,125.46$ 
123.55. MS (ESI+): $\mathrm{m} / \mathrm{z}$ 904.8 $\left[\mathrm{M}-\mathrm{PF}_{6}\right]^{+}$. Elemental Analysis: calcd. for $\mathrm{C}_{55} \mathrm{H}_{40} \mathrm{~F}_{6} \mathrm{~N}_{4} \mathrm{O}_{4} \mathrm{PRu}=\mathrm{C}, 62.76 ; \mathrm{H}, 3.64 ; \mathrm{N}, 5.53$. Found $=\mathrm{C}, 61.67 ; \mathrm{H}, 3.63 ; \mathrm{N}, 5.09$. HPLC: 0-3 minutes: isocratic 65\% A (35\% B); 3-17 minutes: linear gradient from 65\% $\mathrm{A}(35 \% \mathrm{~B})$ to $100 \% \mathrm{~A}(0 \% \mathrm{~B}) ; 17-23$ minutes: isocratic $100 \% \mathrm{~A}(0 \% \mathrm{~B}), \mathrm{T}_{\mathrm{R}}=11.887$ $\min$.

\section{$\left[\mathrm{Ru}(\mathrm{DIP})_{2}(3-\right.$-methylsq $\left.)\right]\left(\mathrm{PF}_{6}\right)(2)$}

Deep red solid (0.07 g, $0.07 \mathrm{mmol}, 24 \%)$. IR (Golden Gate, $\left.\mathrm{cm}^{-1}\right)$ : 3060w, 1600w, 1540m, 1390m, 1250m, 1150m, 1100w, 1030w, 827s, 764s, 735s, 700s. ${ }^{1} \mathrm{H}$ NMR (400 $\left.\mathrm{MHz}, \mathrm{CD}_{2} \mathrm{Cl}_{2}\right) \delta 8.79-8.11$ (br, $6 \mathrm{H}$, arom.), $8.08-7.82$ (br, $6 \mathrm{H}$, arom.), 7.60 (br, $15 \mathrm{H}$, arom.), $7.40-6.81$ (br, $11 \mathrm{H}$, arom.). ${ }^{13} \mathrm{C} \mathrm{NMR}\left(100 \mathrm{MHz}, \mathrm{CD}_{2} \mathrm{Cl}_{2}\right): \delta / \mathrm{ppm}=148.62$, $147.00,142.78,142.70,142.59,136.94,136.22,132.88,130.54,130.25,130.13$ $129.79,129.61,129.56,128.64,126.87,126.52,124.93,124.47,121.72 . \mathrm{MS}(\mathrm{ESI}+)$ : $\mathrm{m} / \mathrm{z} 888.7\left[\mathrm{M}-\mathrm{PF}_{6}\right]^{+}$. Elemental Analysis: calcd. for $\mathrm{C}_{55} \mathrm{H}_{40} \mathrm{~F}_{6} \mathrm{~N}_{4} \mathrm{O}_{3} \mathrm{PRu}=\mathrm{C}, 62.86 ; \mathrm{H}$, 3.84; N, 5.33. Found $=\mathrm{C}, 62.95 ; \mathrm{H}, 3.69 ; \mathrm{N}, 5.20$. HPLC: $0-3$ minutes: isocratic $65 \%$ A (35\% B); 3-17 minutes: linear gradient from 65\% A (35\% B) to $100 \% \mathrm{~A}(0 \% \mathrm{~B}) ; 17-$ 23 minutes: isocratic $100 \% \mathrm{~A}(0 \% \mathrm{~B}), \mathrm{T}_{\mathrm{R}}=13.568 \mathrm{~min}$.

\section{$\left[\operatorname{Ru}(\mathrm{DIP})_{2}\left(4-{\text { methylsq })]\left(\mathrm{PF}_{6}\right)(3)}\right.\right.$}

Deep red solid (0.09 g, $0.09 \mathrm{mmol}, 29 \%)$. IR (Golden Gate, $\left.\mathrm{cm}^{-1}\right)$ : 3060w, 1620w, $1590,1560,1510 \mathrm{w}, 1420 \mathrm{~m}, 1240 \mathrm{~m}, 1120 \mathrm{w}, 1090 \mathrm{w}, 1030 \mathrm{w}, 912 \mathrm{w}, 827 \mathrm{~s}, 762 \mathrm{~s}, 735 \mathrm{~m}$, 698s. ${ }^{1} \mathrm{H}$ NMR (500 MHz, $\left.\mathrm{CD}_{2} \mathrm{Cl}_{2}\right) \delta 8.63-8.07$ (br, 6H, arom.), $8.03-7.81$ (br, 7H, arom.), $7.72-7.36$ (br, 16H, arom.), $7.36-7.03$ (m, 9H, arom.). ${ }^{13} \mathrm{C}$ NMR (125 MHz, $\left.\mathrm{CD}_{2} \mathrm{Cl}_{2}\right): \delta / \mathrm{ppm}=149.08,147.51,143.55,142.50,140.12,140.01,136.57,136.18$ $132.83,132.35,130.28,130.19,129.97,129.60,129.49,128.89,128.71,128.37$ 
126.41, 124.88, 123.69. MS (ESI+): m/z 888.7 [M - PF6] $]^{+}$Elemental Analysis: calcd. for $\mathrm{C}_{55} \mathrm{H}_{38} \mathrm{~F}_{6} \mathrm{~N}_{4} \mathrm{O}_{2} \mathrm{PRu}=\mathrm{C}, 63.95 ; \mathrm{H}, 3.71 ; \mathrm{N}$, 5.42. Found $=\mathrm{C}, 63.84 ; \mathrm{H}, 3.62 ; \mathrm{N}, 5.29$. HPLC: 0-3 minutes: isocratic 85\% A (15\% B); 3-17 minutes: linear gradient from $85 \%$ $\mathrm{A}(15 \% \mathrm{~B})$ to $100 \% \mathrm{~A}(0 \% \mathrm{~B}) ; 17-23$ minutes: isocratic $100 \% \mathrm{~A}(0 \% \mathrm{~B}), \mathrm{T}_{\mathrm{R}}=13.532$ $\min$.

\section{$\left[\mathrm{Ru}(\mathrm{DIP})_{2}\right.$ (4-tert-buthylsq)](PF 6$)(4)$}

Deep red solid (0.05 g, $0.05 \mathrm{mmol}, 16 \%)$.IR (Golden Gate, $\mathrm{cm}^{-1}$ ): 3060w, 2960w, $1620 \mathrm{w}, 1580 \mathrm{w}, 1510 \mathrm{~m}, 1450 \mathrm{~m}, 1420 \mathrm{~m}, 1220 \mathrm{~m}, 1090 \mathrm{w}, 1030 \mathrm{w}, 827 \mathrm{~s}, 764 \mathrm{~s}, 735 \mathrm{~s}, 700 \mathrm{~s}$. ${ }^{1} \mathrm{H}$ NMR (400 MHz, $\mathrm{CD}_{2} \mathrm{Cl}_{2}$ ): $\delta / \mathrm{ppm}=8.43-8.12$ (br, 6H, arom.), $8.09-7.81$ (br, $9 \mathrm{H}$, arom.), $7.70-7.46$ (br, 16H, arom.), $7.46-7.24$ (br, 4H, arom.), $7.24-7.04$ (br, 8H, arom.). ${ }^{13} \mathrm{C} \mathrm{NMR}\left(125 \mathrm{MHz}, \mathrm{CD}_{2} \mathrm{Cl}_{2}\right): \delta / \mathrm{ppm}=147.51,147.31,143.70,136.70$, $136.64,132.77,132.54,130.21,129.63,129.45,128.84,128.75,127.49,126.60$, 124.85, 124.45. $\mathrm{MS}(\mathrm{ESI}+): \mathrm{m} / \mathrm{z} 930.8\left[\mathrm{M}-\mathrm{PF}_{6}\right]^{+}$. Elemental Analysis: calcd. for $\mathrm{C}_{58} \mathrm{H}_{44} \mathrm{~F}_{6} \mathrm{~N}_{4} \mathrm{O}_{2} \mathrm{PRu}=\mathrm{C}, 64.80 ; \mathrm{H}, 4.13 ; \mathrm{N}, 5.21$. Found $=\mathrm{C}, 64.72 ; \mathrm{H}, 4.13 ; \mathrm{N}, 5.14$. HPLC: $0-3$ minutes: isocratic $85 \%$ A $(15 \% \mathrm{~B}) ; 3-7$ minutes: linear gradient from $85 \%$ A $(15 \% \mathrm{~B})$ to $100 \% \mathrm{~A}(0 \% \mathrm{~B})$; 7-9 minutes: isocratic $100 \% \mathrm{~A}(0 \% \mathrm{~B})$; $9-11$ minutes: linear gradient from $100 \% \mathrm{~A}$ to $85 \% \mathrm{~A}, \mathrm{~T}_{\mathrm{R}}=9.801 \mathrm{~min}$.

\section{$\operatorname{Ru}(\mathrm{DIP})_{2}$ (tetrabromocat) (5)}

Blue/violet solid (0.192 g, $0.162 \mathrm{mmol}, 54 \%$ ). IR (Golden Gate, $\mathrm{cm}^{-1}$ ) : 3060w, 1600w, 1430s, 1260m, 1080m, 1030w, 914m, 847m, 760m, 731m, 700s. ${ }^{1} \mathrm{H}$ NMR (400 MHz, $\mathrm{CD}_{2} \mathrm{Cl}_{2}$ ): $\delta / \mathrm{ppm}=8.14-8.03$ (br, $5 \mathrm{H}$, arom.), $7.74-7.63$ (br, $10 \mathrm{H}$, arom.), $7.60-7.43$ (br, $15 \mathrm{H}$, arom.), $7.40-7.31$ (br, $2 \mathrm{H}$, arom.). $\left.{ }^{13} \mathrm{C} \mathrm{NMR} \mathrm{(125} \mathrm{MHz,} \mathrm{CD}_{2} \mathrm{Cl}_{2}\right): \delta / \mathrm{ppm}=$ $146.27,145.67,145.62,145.27,136.94,132.87,132.83,132.76,132.64,132.56$, 
$130.25,130.19,129.62,129.46,129.35,128.46,126.44,129.35,128.46,126.44$ 126.38, 125.74, 125.66. MS (ESI+): m/z 1090.4 [M] $]^{+}$. Elemental Analysis: calcd. for $\mathrm{C}_{54} \mathrm{H}_{32} \mathrm{Br}_{4} \mathrm{~N}_{4} \mathrm{O}_{2} \mathrm{Ru}=\mathrm{C}, 54.52 ; \mathrm{H}, 2.71 ; \mathrm{N}, 4.71$. Found = C, 54.56; H, 2.37; N, 4.89. HPLC: 0-3 minutes: isocratic 85\% A (15\% B); 3-7 minutes: linear gradient from 85\% A $(15 \% \mathrm{~B})$ to $100 \% \mathrm{~A}(0 \% \mathrm{~B}) ; 7-9$ minutes: isocratic $100 \% \mathrm{~A}(0 \% \mathrm{~B}) ; 9-11$ minutes: linear gradient from $100 \% \mathrm{~A}$ to $85 \% \mathrm{~A}, \mathrm{~T}_{\mathrm{R}}=8.623 \mathrm{~min}$.

\section{$\operatorname{Ru}(\mathrm{DIP})_{2}$ (4-nitrocat) (6)}

Blue/violet solid $(0.07 \mathrm{~g}, 0.08 \mathrm{mmol}, 27 \%)$. IR (Golden Gate, $\left.\mathrm{cm}^{-1}\right): 3060 \mathrm{w}, 1550 \mathrm{w}$, 1490m, 1410w, 1240s, 1120m, 1070s, 1030w, 949w, 910w, 845s, 762s, 733s, 698s. ${ }^{1} \mathrm{H}$ NMR (400 MHz, $\mathrm{CD}_{2} \mathrm{Cl}_{2}$ ): $\delta / \mathrm{ppm}=9.65-9.21$ (br, 3H, arom.), $8.24-7.85$ (br, $8 \mathrm{H}$, arom.), $7.81-7.40$ (br, 17H, arom.), $7.41-7.18$ (br, 2H, arom.), $6.87-6.59$ (br, $1 \mathrm{H}$, arom.), $6.60-6.27$ (br, 2H, arom.), $6.11-5.84$ (br, 2H, arom.). ${ }^{13} \mathrm{C}$ NMR (125 MHz, $\left.\mathrm{CD}_{2} \mathrm{Cl}_{2}\right): \delta / \mathrm{ppm}=153.27,152.64,152.53,150.58,146.76,146.65,144.72,144.63$, $137.40,137.17,130.79,130.69,130.19,129.61,129.50,129.44,128.86,128.38$, 126.17, 125.87, 125.49, 125.15, 124.99, 124.87. MS (ESI+): m/z 919.4 [M] ${ }^{+}$. Elemental Analysis: calcd. for $\mathrm{C}_{54} \mathrm{H}_{39} \mathrm{~N}_{5} \mathrm{O}_{6} \mathrm{Ru}=\mathrm{C}, 67.92 ; \mathrm{H}, 4.12 ; \mathrm{N}, 7.33$. Found $=\mathrm{C}, 68.04 ; \mathrm{H}$, 4.11; N, 7.28. HPLC: 0-3 minutes: isocratic 5\% A (95\% B); 3-17 minutes: linear gradient from $5 \% \mathrm{~A}(95 \% \mathrm{~B})$ to $100 \% \mathrm{~A}(0 \% \mathrm{~B}) ; 17-23$ minutes: isocratic $100 \% \mathrm{~A}$ $(0 \% \mathrm{~B}), \mathrm{T}_{\mathrm{R}}=15.907 \mathrm{~min}$.

\section{Electrochemical Measurements}

The electrochemical experiments were carried out with a conventional three-electrodes cell (solution volume of $15 \mathrm{~mL}$ ) and a PC-controlled potentiostat/galvanostat (Princeton Applied Research Inc. model 263A). The working electrode was a vitreous 
carbon electrode from Origalys (France) exposing a geometrical area of $0.071 \mathrm{~cm}^{2}$ and mounted in Teflon ${ }^{\circledR}$. The electrode was polished before each experiment with 3 and 0.3 $\mu \mathrm{m}$ alumina paste followed by extensive rinsing with ultra-pure Milli-Q water. Platinum wire was used as the counter electrode and saturated calomel electrode, SCE, as the reference electrode. Electrolytic solutions, DMF containing tetrabutylammonium hexafluorophosphate $0.1 \mathrm{M}\left(\mathrm{NBu}_{4} \mathrm{PF}_{6}\right.$, Aldrich, +99\%) as supporting electrolyte, were routinely deoxygenated by argon bubbling. All the potential values are given versus the calomel saturated electrode SCE and recalculated versus the $\mathrm{Me}_{10} \mathrm{Fc}^{0 /+}$ redox pair $\left(E_{1 / 2}\right.$ $=0.04 \mathrm{~V} v s . \mathrm{SCE})$.

\section{Computational Details}

All structural optimizations were performed using the Gaussian 16 suite of programs ${ }^{81}$, at unrestricted Kohn-Sham ${ }^{82}$ (UKS) level. The non-relativistic double-zeta LANL2DZ ${ }^{83}$ pseudopotential (effective-core-potential, ECP) were used for Ru and $\mathrm{Br}$ atoms, together with the Pople split valence double-zeta basis set for $\mathrm{C}, \mathrm{N}, \mathrm{O}, \mathrm{S}$, and $\mathrm{H}$, coupled with one set of polarization and diffuse functions ${ }^{84-86}$ on all atoms, except for hydrogens. The B3LYP ${ }^{87}$ exchange-correlation functional was used throughout. Solvent effects (isopropanol) were taken into account using the polarized continuum model in its conductor-like version $(\mathrm{CPCM}){ }^{88}$

Calculations of g-tensors were performed on optimized structures using the Orca 3.0.3 Package. ${ }^{89}$ Scalar relativistic effects were included using the zero-order regular approximation (ZORA). ${ }^{90,91} \mathrm{~A}$ common gauge origin at the metal nucleus was employed. Such calculations were performed using the segmented all-electron relativistically contracted (SARC) def2-SVP ${ }^{92}$ basis on all atoms except for the Ruthenium atoms, for which the def2-TZVP(-f) basis sets was used. The calculations 
were sped up by employing the chain-of-sphere (RIJCOSX) ${ }^{93}$ approximation along with the decontracted auxiliary basis set of def2-SVP/J coulomb-fitting. ${ }^{94}$ Increased integration grids (Grid4) and tight SCF convergence were used throughout the calculations. Solvent effects have been taken into account with conductor-like screening model (COSMO) with a dielectric constant $\varepsilon$ of $20.7^{95}$ - closest value to the isopropanol environment simulated in the geometry optimization.

\section{Electron Paramagnetic Resonance Spectroscopy}

Electron paramagnetic resonance (EPR) experiments were performed on a MiniScope MS400 table-top X-band spectrometer from Magnettech. Simulation of the experimental EPR spectra was performed with the MATLAB EasySpin program. ${ }^{96}$ All samples were dissolved in dry and $\mathrm{N}_{2}$-saturated DCM at a concentration of ca. $1 \mathrm{mM}$. Oxidized forms were generated using ferrocenium hexafluoroantimonate ( $\mathrm{FcPF}_{6}, E_{1 / 2}$ $=0.450 \mathrm{~V}$ vs SCE in DMF/0.1 M NBu4PF6). ${ }^{49,97}$

\section{UV/Vis/NIR Spectroelectrochemistry (UV/Vis/NIR-SEC)}

UV/Vis/NIR spectra were recorded on a TIDAS fibreoptic diode array spectrometer (combined MS UV/NIR and PGS NIR instrumentation) from J\&M in HELLMA quartz cuvettes with a $0.1 \mathrm{~cm}$ optical path length. The OTTLE (optically transparent thin layer electrolysis) cell used for spectroelectrochemical studies was lab-built according to the design by Hartl et. al. ${ }^{98}$ and comprises a Pt-mesh working electrode, a Pt-sheet counter electrode and a Ag-sheet pseuoreference electrode sandwiched between $\mathrm{CaF}_{2}$ windows. For regular absorption spectra dry DMF was used as the solvent, while SEC experiments were conducted in a DMF electrolyte containing $0.1 \mathrm{M}$ of $\mathrm{NBu}_{4} \mathrm{PF}_{6}$. A BASi potentiostat was used to apply the necessary voltage to generate the reduced/oxidized species. 


\section{Stability studies}

The stability in DMSO-d6 at room temperature was assessed by ${ }^{1} \mathrm{H}$ NMR over $96 \mathrm{~h}$. The stability of complex $\mathbf{1}$ in human plasma at $37^{\circ} \mathrm{C}$ was evaluated following a slightly modified procedure already reported by our group. ${ }^{29}$ The human plasma was provided by Biowest. Caffeine (internal standard) was obtained from TCI Chemicals. Stock solutions of the complexes (10 $\mathrm{mM}$ in DMSO) and caffeine (10 $\mathrm{mM}$ in milliQ water) were prepared. An aliquot of the respective stock solutions was then added to the plasma solution $(380 \mu \mathrm{L})$ to a total volume of $500 \mu \mathrm{L}$ and final concentrations of 400 $\mu \mathrm{M}$ for the complexes and $2 \mathrm{mM}$ for caffeine. The resulting plasma solution was incubated for either $0,1,3,5,16$ or $24 \mathrm{~h}$ at $37^{\circ} \mathrm{C}$ with continuous and gentle shaking (ca. $600 \mathrm{rpm}$ ). The reaction was stopped by addition of $1 \mathrm{~mL}$ of methanol, and the mixture was centrifuged for $3 \mathrm{~min}$ at $2000 \mathrm{rpm}$ at room temperature. The methanolic solution was directly analysed using HPLC with a total injection volume of $20 \mu \mathrm{L}$. HPLC: 0-3 minutes: isocratic 85\% A (15\% B); 3-7 minutes: linear gradient from $85 \%$ $\mathrm{A}(15 \% \mathrm{~B})$ to $100 \% \mathrm{~A}(0 \% \mathrm{~B}) ; 17-22$ minutes: isocratic $100 \% \mathrm{~A}(0 \% \mathrm{~B}), \mathrm{T}_{\mathrm{R}(\mathrm{caff})}=3.38$ $\min , \mathrm{T}_{\mathrm{R}(1)}=6.51 \mathrm{~min}$.

\section{Cell culture}

HeLa and CT-26 cell lines were cultured in DMEM media (Gibco) supplemented with $10 \%$ of fetal calf serum (Gibco). CT-26 LUC cell line was cultured in DMEM media (Gibco) supplemented with $10 \%$ of fetal calf serum (Gibco) and $1 \%$ Genticin. RPE-1 cell line was cultured in DMEM/F-12 media (Gibco) supplemented with 10\% of fetal calf serum. A2780, A2780 cis, A2780 ADR cell lines were cultured in RPMI 1640 media (Gibco) supplemented with $10 \%$ of fetal calf serum (Gibco). The resistance of A2780 cis was maintained by cisplatin treatment $(1 \mu \mathrm{M})$ for one week every month. The 
cells were used in the assays after one week from the end of the treatment in order to avoid interfered results. The resistance of A2780 ADR was maintained by doxorubicin treatment $(0.1 \mu \mathrm{M})$ once a week. Cells were used in the assays after three days post doxorubicin treatment in order to avoid interfered results. Cell lines were complemented with $100 \mathrm{U} / \mathrm{ml}$ penicillin-streptomycin mixture (Gibco) and maintained in humidified atmosphere at $37{ }^{\circ} \mathrm{C}$ and $5 \%$ of $\mathrm{CO}_{2}$.

\section{Cytotoxicity assay using a 2D cellular model}

Cytotoxicity of the tested $\mathrm{Ru}$ complex was assessed by a fluorometric cell viability assay using Resazurin (ACROS Organics). Briefly, cells were seeded in triplicates in 96-well plates at a density of $4 \times 10^{3}$ cells/well in $100 \mu \mathrm{L}$. After $24 \mathrm{~h}$, cells were treated with increasing concentrations of the ruthenium complexes and ligands. Dilutions for complexes 1-4 were prepared as follows: $1.25 \mathrm{mM}$ stock in DMSO was diluted to 100 $\mu \mathrm{M}$ with media and then filtrated $(0.22 \mu \mathrm{m}$ filter VWR). Dilutions for complexes $\mathbf{5 , 6}$ were prepared as follows: $1.25 \mathrm{mM}$ stock in DMF was diluted to $100 \mu \mathrm{M}$ with media and then filtrated $\left(0.22 \mu \mathrm{m}\right.$ filter VWR). For $\mathbf{R u}(\mathbf{D I P})_{2} \mathbf{C l}_{2} 2.5 \mathrm{mM}$ stock in DMF was prepared, which was further diluted to $100 \mu \mathrm{M}$ and filtrated $(0.22 \mu \mathrm{m}$ filter VWR). After $48 \mathrm{~h}$ incubation, medium was removed, and $100 \mu \mathrm{L}$ of complete medium containing resazurin $(0.2 \mathrm{mg} / \mathrm{mL}$ final concentration) was added. After $4 \mathrm{~h}$ of incubation at $37^{\circ} \mathrm{C}$, the fluorescence signal of resorufin product was read (ex: $540 \mathrm{~nm}$ em: $590 \mathrm{~nm}$ ) in a SpectraMax M5 microplate Reader. IC50 values were then calculated using GraphPad Prism software.

\section{Generation of 3D HeLa MCTS}

MCTS were cultured using ultra-low attachment 96 wells plates from Corning ${ }^{\circledR}$ (Fisher Scientific 15329740). HeLa cells were seeded at a density of 5000 cells per well in 200 
$\mu \mathrm{L}$. The single cells would generate MCTSs approximately $400 \mu \mathrm{m}$ in diameter at day 4 with $37^{\circ} \mathrm{C}$ and $5 \% \mathrm{CO}_{2}$.

\section{Treatment of 3D HeLa MCTS}

After 4 days of growing at $37{ }^{\circ} \mathrm{C}$ and $5 \% \mathrm{CO}_{2}$, were treated by replacing half of the medium in the well with increasing concentration of compounds for $48 \mathrm{~h}$ in the dark. For untreated reference MCTS, half of the medium was replaced by fresh medium only. The cytotoxicity was measured by ATP concentration with CellTiter-Glo ${ }^{\circledR}$ Cell viability kit (Promega, USA).

\section{HeLa MCTSs growth inhibition}

MCTSs were grown and treated as described above. MCTSs sizes were observed under a light microscope and pictures were taken with an iPhone 6s thanks to a phone microscope adaptor. Before imaging, the plate was shaken, and half of the media was exchanged to remove dead cells. Images were recorded before treatment (day 0) and at day 3, 6, 9 and 13 after treatment. Pictures were first processed using GIMP a crossplatform image editor with a batch automation plug-in. The MCTSs sizes were then calculated with SpheroidSizer, a MATLAB-based and open-source software application to measure the size of tumour spheroids automatically and accurately. Data analysis was done using GraphPad Prism software.

\section{Annexin V / PI assay}

Apoptosis and necrosis induction in HeLa cells treated with complex 1 was evaluated via an AnnexinV/PI staining assay using flow cytometry. Briefly, cells were seeded at density of $2 \times 10^{6}$ cells in $10 \mathrm{~cm}$ cell culture dish $24 \mathrm{~h}$ prior cell treatments. The medium was removed and replaced with $10 \mu \mathrm{M}$ solution of complex 1 or $1 \mu \mathrm{m}$ Staurosporin (positive control -Abcam Cat no.120056) and further incubated for $30 \mathrm{~min}, 4 \mathrm{~h}$ or $24 \mathrm{~h}$. Cells were collected, washed twice with ice cold PBS and resuspended in 1x Annexin 
V binding buffer (10 x buffer composition: 0,1 M HEPES (pH 7.4), 1.4 M NaCl. 25 $\mathrm{mM} \mathrm{CaCl} 2$ ). Samples were processed according to the manufacturer instructions (BD Scientific, cat. no. 556463 and 556419) and analysed using ZE5 Biorad instrument at Cytometry Platform at Institute Curie. Data were analysed using the FlowJo software.

\section{Sample Preparation for cellular uptake}

Cells were seeded at density of $2 \times 10^{6}$. Next day, cells were treated with $5 \mu \mathrm{M}$ concentration of $\mathbf{1}$ or $\mathbf{R u C l}_{\mathbf{2}}(\mathbf{D I P})_{2}$. After $2 \mathrm{~h}$, cells were collected, counted and snap frozen in liquid nitrogen and stored at $-20^{\circ} \mathrm{C}$. ICP-MS samples were prepared as follows: samples were digested using $70 \%$ nitric acid $\left(1 \mathrm{~mL}, 60^{\circ} \mathrm{C}\right.$, overnight). Samples were then further diluted 1:100 (1\% $\mathrm{HCl}$ solution in MQ water) and analysed using ICP-MS.

\section{Sample Preparation for cellular fractionation}

HeLa cells were seeded in three $15 \mathrm{~cm}^{2}$ cell culture dishes so that on the day of treatment cells were $90 \%$ confluent. On the day of treatment cells were incubated with the target complex at a concentration of $5 \mu \mathrm{M}$ for $2 \mathrm{~h}$. After that time, the medium was removed; cells were washed, collected and counted. After resuspension in cold PBS, the organelles were isolated via different protocols (one cell culture dish per isolation was used).

Mitochondria isolation: To isolate mitochondria, a Mitochondria Isolation Kit (Cat. Nr: MITOISO2, Sigma Aldrich) was used according to the manufacturer procedure for isolation of mitochondria via homogenization method.

Lysosome isolation: To isolate lysosomes, a Lysosome Isolation Kit (Cat. Nr: LYSISO1, Sigma Aldrich) was used, according to the manufacturer procedure for isolation of lysosomes via Option C. 
Nuclear and cytoplasm isolation: To isolate nuclear and cytoplasmic fractions, the ROCKLAND nuclear extract protocol was used. ${ }^{99}$ Briefly cells were collected by centrifugation, resuspended in cytoplasmic extraction buffer and incubated on ice. The tubes were centrifuged and supernatant (CE) was removed. Pellets were washed with cytoplasmic extraction buffer without detergent and centrifuged. The pellet (NE) was resuspended in nuclear extraction buffer and incubated on ice. Both CE and NE were centrifuged. Supernatant from CE samples was indicated as cytoplasmic extract, whereas the pellet obtained from NE samples was indicated as nuclear extract.

ICP-MS samples were prepared as follows: isolated cellular fractions were lyophilised and digested using $5 \mathrm{~mL}$ of $70 \%$ nitric acid $\left(60{ }^{\circ} \mathrm{C}\right.$, overnight). Samples were then further diluted (1:1000 for nuclear pellet samples and 1:100 for all the other samples) MQ water (containing in 1\% $\mathrm{HCl}$ solution) and analysed using ICP-MS.

\section{Sample preparation for studies on the mechanism of cellular uptake}

Samples were prepared as previously reported. ${ }^{29}$ Briefly, HeLa cells were seeded at density of $2 \times 10^{6}$ and next day were pre-treated with corresponding inhibitors or kept at specific temperature for $1 \mathrm{~h}$. Next, cells were washed with PBS and were incubated with $5 \mu \mathrm{M}$ of complex 1 for $2 \mathrm{~h}$ (low temperature sample was still kept at $4{ }^{\circ} \mathrm{C}$ ). Afterwards cells were washed with PBS, collected, counted and snap frozen in liquid nitrogen. Pellets were stored at $-20^{\circ} \mathrm{C}$. ICP-MS samples were prepared as follows: samples were digested using $70 \%$ nitric acid $\left(1 \mathrm{~mL}, 60{ }^{\circ} \mathrm{C}\right.$, overnight), further diluted 1:100 ( $1 \% \mathrm{HCl}$ solution in MQ water) and analysed using ICP-MS.

\section{DNA metalation of HeLa cells}

Cells were seeded at density of $2 \times 10^{6}$. The following day, cells were treated with 5 
$\mu \mathrm{M}$ concentration of 1 or cisplatin. After $2 \mathrm{~h}$, cells were collected, snap frozen in liquid nitrogen and stored at $-20{ }^{\circ} \mathrm{C}$. The following day, DNA was extracted using a PureLink $^{\mathrm{TM}}$ Genomic DNA Mini Kit (Invitrogen). DNA purity was checked by absorbance measurements at 260 and $280 \mathrm{~nm}$. Concentrations of genomic DNA were calculated assuming that one absorbance unit equals $50 \mu \mathrm{g} / \mathrm{mL}$. ICP-MS samples were prepared as follows: samples were digested using $70 \%$ nitric acid $\left(60{ }^{\circ} \mathrm{C}\right.$, overnight $)$ in 1:1.6 DNA to acid volume ratio. Samples were then further diluted $1: 10$ or $1: 100(1 \%$ $\mathrm{HCl}$ solution in MQ water) and analysed using ICP-MS.

\section{ICP-MS studies}

All ICP-MS measurements were performed on an high resolution ICP-MS (Element II, ThermoScientific) located at the Institut de physique du globe de Paris (France). The

monitored isotopes are ${ }^{101} \mathrm{Ru}$ and ${ }^{195} \mathrm{Pt}$. Daily, prior to the analytical sequence, the instrument was first tuned to produce maximum sensitivity and stability while also maintaining low uranium oxide formation $(\mathrm{UO} / \mathrm{U} \leq 5 \%)$. The data were treated as follow: intensities were converted into concentrations using uFREASI (user-FRiendly Elemental dAta proceSsIng ). ${ }^{100}$ This software, made for HR-ICP-MS users community, is free and available on http://www.ipgp.fr/ tharaud/uFREASI.

\section{ICP-MS data analysis}

Cellular uptake studies: The amount of metal detected in the cell samples was transformed from ppb into $\mu \mathrm{g}$ of metal. Data were subsequently normalised to the number of cells and expressed as $\mu$ mol of metal/ amount of cells.

Cellular fractionation: The amount of detected ruthenium in the cell samples was transformed from $\mathrm{ppb}$ into $\mu \mathrm{g}$ of ruthenium. Values were then normalised to the number 
of cells used for specific extraction. Due to low yield of lysosome extraction (only $25 \%$ ), the values obtained were multiplied by the factor of 4 . Because of a low yield of mitochondria extraction ( $50 \%$ of the cells were homogenized), the values obtained for that organelle were multiplied by the factor of 2. Extraction protocols allow for the isolation of pure subcellular fractions. Therefore, the total amount of metal found in the cells was calculated summing the values obtained for the pure organelles.

Mechanism of uptake: The amount of ruthenium detected in cell samples was transformed from ppb into $\mu \mathrm{g}$ of ruthenium and values obtained were normalised to the number of cells used for specific treatment. The value for the ruthenium found in the $37{ }^{\circ} \mathrm{C}$ sample was used as a $100 \%$.

Cellular metalation: The amount of ruthenium detected in cell samples was transformed from ppb into $\mu \mathrm{g}$ of ruthenium and value obtained was normalised to the amount of DNA.

Biodistribution study: The amount of ruthenium detected in organ digests was transformed from ppb into $\mu \mathrm{g}$ of ruthenium per g of tissue.

\section{JC-1 Mitochondrial Membrane Potential Test}

HeLa cells were seeded at a density of 6000 cells / well in black 96 well-plates (Costar 3916). The following day, cells were treated with different concentrations of 1 and $\mathbf{R u C l}_{\mathbf{2}}(\mathbf{D I P})_{2}$. After further $24 \mathrm{~h}$, cells were treated according to the instructions of the JC-1 Mitochondrial Membrane Potential Assay Kit (Abcam, ab113850). The data were analysed using GraphPad Prism software.

\section{Metabolic Studies}


HeLa cells were seeded in Seahorse XFe96 well plates at a density of 30,000 cells / well in $80 \mu \mathrm{L}$ medium. After $24 \mathrm{~h}$, the medium was replaced with fresh medium and cisplatin $(1 \mu \mathrm{M})$, doxorubicin $(1 \mu \mathrm{M})$, 3-Methoxycatechol $(1 \mu \mathrm{M})$, complex $\mathbf{R u C l}_{2}(\mathbf{D I P})_{2}(1 \mu \mathrm{M})$ or complex $\mathbf{1}(1 \mu \mathrm{M})$ were added. After $24 \mathrm{~h}$ of incubation, the regular medium was removed, cells were washed thrice using Seahorse Base Media and incubated in a non- $\mathrm{CO}_{2}$ incubator at $37^{\circ} \mathrm{C}$ for $1 \mathrm{~h}$.

Mito Stress Test: Mitostress assay was run using Oligomycin, $1 \mu \mathrm{M}, \mathrm{FCCP} 1 \mu \mathrm{M}$ and mixture of Antimycin-A/ Rotenone $1 \mu \mathrm{M}$ each in ports $\mathrm{A}, \mathrm{B}$ and $\mathrm{C}$ respectively using Seahorse XFe96 Extracellular Flux Analyzer.

Glycolysis Stress Test: Glycolytic stress test was run using glucose (10 mM), Oligomycin $(1 \mu \mathrm{M})$ and 2-Deoxyglucose $(50 \mathrm{mM})$ in ports $\mathrm{A}, \mathrm{B}$ and $\mathrm{C}$ respectively using Seahorse XFe96 Extracellular Flux Analyzer.

Mito Fuel Flex Test: Fuel flex assay for the different fuel pathways viz. glucose, glutamine and fatty acid was studied by measuring the basal oxygen consumption rates and that after addition of the inhibitor of the target pathway in port A and a mixture of the inhibitors of the other two pathways in port B. This gave a measure of the dependency of the cells on a fuel pathway. To study the capacity of a certain fuel pathway, the sequence of addition of the inhibitors was reversed. In port A was added the mixture of inhibitors for the other pathways and in port B was added the inhibitor for the target pathway. UK-5099 (pyruvate dehydrogenase inhibitor, $20 \mu \mathrm{M}$ ) was used as an inhibitor for the glucose pathway. BPTES (selective inhibitor of Glutaminase GLS1, $30 \mu \mathrm{M}$ ) was used as an inhibitor for the glutamine pathway. Etomoxir (Ocarnitine palmitoyltransferase-1 (CPT-1) inhibitor, $40 \mu \mathrm{M})$ was used as an inhibitor for the fatty acid pathway. 


\section{Formulation of compound 1 in polysorbate 80}

Formulation protocol: Compound $\mathbf{1}$ was formulated in polysorbate 80 using the film rehydration method. Briefly, compound $1(2 \mathrm{mg}, 2.2 \mu \mathrm{mol})$ and polysorbate 80 (100 $\mathrm{mg})$ were dissolved in acetone $(3 \mathrm{~mL})$. The solvent was removed by rotary evaporation at $40{ }^{\circ} \mathrm{C}$. The red film was then resuspended in PBS $(2 \mathrm{~mL})$ at room temperature. The solution was finally sterile-filtered on a $0.20 \mu \mathrm{m}$ nylon membrane (Corning $\left.{ }^{\circledR} 431224\right)$ to yield a clear red solution.

Compound concentration determination: $50 \mu \mathrm{L}$ of the sample was diluted in $100 \mu \mathrm{L}$ of acetonitrile and the absorbance was recorded at $480 \mathrm{~nm}$ in 96 wells plates from Corning $^{\circledR}$ (Fisher Scientific 15329740) using a SpectraMax M5 microplate Reader. The measure was performed in triplicates and compound $\mathbf{1}$ concentration was determined using a calibration curve obtained in the same conditions $(50 \mathrm{mg} / \mathrm{mL}$ polysorbate 80 in PBS/acetonitrile 1:3). Encapsulation efficiency was calculated by comparing the absorbance of the solution before and after filtration using the following equation.

$$
\text { Encapsulation efficiency }=100 * \frac{\text { Absorbance after filtration }}{\text { Absorbance before filtration }}
$$

To ensure its repeatability, the procedure was performed in triplicate.

\section{Biodistribution study}

This study was carried out in accordance with EU regulations and approved by the Ethical Commission of the faculty of Pharmaceutical and Biological Sciences ParisDescartes (agreement number: E-75-06-02).

8-week old BALB/c mice (Janvier) were separated into three groups and injected intravenously with $5 \mathrm{mg} / \mathrm{kg}$ of compound 1 formulated in polysorbate $80(280 \mathrm{mg} / \mathrm{kg})$ 
and PBS. After 30 minutes, 1 or 2 hours, mice were sacrificed and relevant organs including blood, liver, lungs, brain, intestine, spleen and kidneys were harvested, weighed, and digested using $70 \%$ nitric acid $\left(5 \mathrm{~mL}, 60^{\circ} \mathrm{C}, 24 \mathrm{~h}\right.$ or $48 \mathrm{~h}$ for intestines), further diluted in 1:100 (1\% $\mathrm{HCl}$ solution in MQ water) and analyzed using ICP-MS.

\section{Associated Content}

\section{Supporting Information}

The Supporting Information is at DOI: XXXXX.

$\mathrm{UV} / \mathrm{Vis} / \mathrm{NIR}$ absorptions of the complexes in their native and electrochemically generated states in DMF (Table S1), NMR spectra of complexes 1-6 (Figure S1), HPLC traces at $450 \mathrm{~nm}$ of complexes 1-6 (Figure S2), EPR spectra (Figure S3), Computed and Experimental g-Tensors (Table S2), Votammograms recorded by CV and with the use of RDE for complexes 2-6 (Figure S4), Electrochemical data for complexes 1-4 (Table S3), UV/Vis/NIR-spectroelectrochemistry data for complex 1 in the presence of the reducing agent glutathione (Figure S5), Electrochemical data for complexes 5 and 6 (Table S4), Overlap of ${ }^{1} \mathrm{H}$ spectra of complexes 1-6 in DMSO-d 6 over 96 h (Figure S6), Percentage concentration of complex 1 in human plasma, normalized with respect to the internal standard (caffeine) and plotted against time (Figure S7), Fluorometric cell viability assay (Figure S8), IC50 values for catechols (Table S5), CellTiter Glo ${ }^{\circledR}$ viability Test (Figure S9), Cell Death Mechanism (Figure S10), Cellular uptake mechanism of complex 1 (Figure S11), Oxygen consumption rates and different respiration parameters in HeLa cells alone or after treatment with various test compounds (Figure S12), Extracellular acidification rate and different 
parameters during glycolysis in HeLa cells alone or after treatment with various test compounds (Figure S13) and Fuel flex assay in HeLa cells (Figure S14).

\section{Acknowledgements}

This work was financially supported by an ERC Consolidator Grant PhotoMedMet to G.G. (GA 681679) and has received support under the program Investissements d'Avenir launched by the French Government and implemented by the ANR with the reference ANR-10-IDEX-0001-02 PSL (G.G.). Ile de France Region is gratefully acknowledged for financial support of $500 \mathrm{MHz}$ NMR spectrometer of Chimie ParisTech in the framework of the SESAME equipment project. We acknowledge the loan of Agilent's equipment to Chimie ParisTech. This project has received funding from the European Research Council (ERC) under the European Union's Horizon 2020 research and innovation programme (grant agreement No 648558, STRIGES CoG grant to I.C.). Part of this work was supported by IPGP multidisciplinary program PARI and by Region Île-de-France SESAME Grant no. 12015908. The authors would like to thank the LIOPA (the small animal optical imaging platform) and the Animal facility of the faculty of pharmacy from Université de Paris, UTCBS, CNRS, INSERM, F-75006 Paris, France.

\section{TOC}

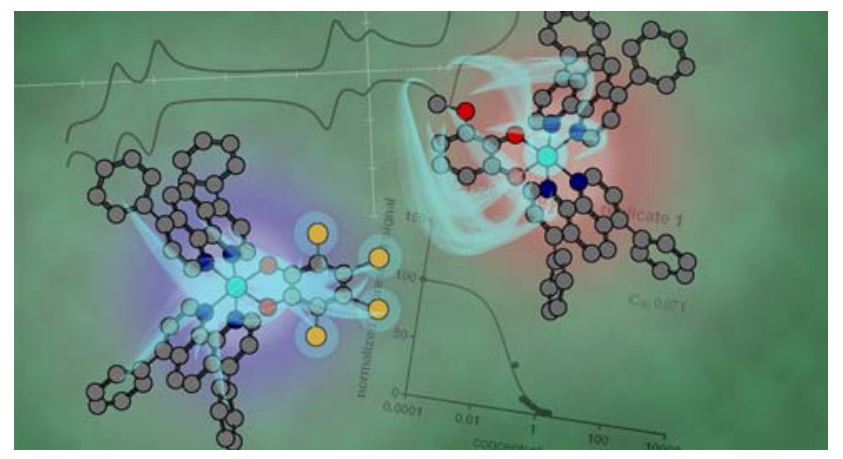




\section{References}

(1) Rosenberg, B. B. Some Biological Effects of Platinum Compounds. Platin. Met. Rev. 1971, 15 (2), 42-51.

(2) Wong, E.; Giandomenico, C. M. Current Status of Platinum-Based Antitumor Drugs. Chem. Rev. 1999, 99 (August), 2451-2466. https://doi.org/10.1021/cr980420v.

(3) Rosenberg, B.; Van Camp, L.; Krigas, T. Inhibition of Cell Division in Escherichia Coli by Electrolysis Products from a Platinum Electrode. Nature 1965, 205, 698-699. https://doi.org/10.1038/205698a0.

(4) Rosenberg, B.; van Camp, L.; Grimley, E. B.; Thomson, A. J. The Inhibition of Growth or Cell Division in Escherichia Coli by Different Ionic Species of Platinum (IV) Complexes. J. Biol. Chem. 1967, 242 (6), 1347-1352.

(5) Rosenberg, B.; Van Camp, L.; Trosko, J. E.; Mansour, V. H. Platinum Compounds: A New Class of Potent Antitumour Agents. Nature 1969, 222 (5191), 385-386. https://doi.org/10.1038/222385a0.

(6) Pieter, P.; Lippard, S. J. Cisplatin and Related Drugs. Encycl. Cancer 1997, 1, 525-543. https://doi.org/http://dx.doi.org/10.1016/B0-12-227555-1/00506-2.

(7) Fricker, S. P. Metal Based Drugs: From Serendipity to Design. Dalton Trans. 2007, 43, 4903-4917. https://doi.org/10.1039/B705551J.

(8) Singh, V.; Azad, G. K.; Reddy M., A.; Baranwal, S.; Tomar, R. S. Anti-Cancer Drug KP1019 Induces Hog1 Phosphorylation and Protein Ubiquitylation in Saccharomyces Cerevisiae. Eur. J. Pharmacol. 2014, 736, 77-85. https://doi.org/10.1016/j.ejphar.2014.04.032.

(9) Jamieson, E.; Lippard, S. Structure, Recognition , and Processing of Cisplatin DNA Adducts. Chem. Rev. 1999, 99 (9), 2467-2498. https://doi.org/10.1021/cr980421n.

(10) Clarke, M. J.; Zhu, F.; Frasca, D. R. Non-Platinum Chemotherapeutic Metallopharmaceuticals. Chem. Rev. 1999, 99 (9), 2511-2533. https://doi.org/10.1021/cr9804238. 
(11) Jakupec, M.; Galanski, M.; Arion, V. B.; Hartinger, C. G.; Keppler, B. K. Antitumour Metal Compounds: More than Theme and Variations. Dalton Trans. 2008, No. 2, 183-194. https://doi.org/10.1039/b712656p.

(12) Dyson, P. J.; Sava, G. Metal-Based Antitumour Drugs in the Post Genomic Era. Dalton Trans. 2006, No. 16, 1929-1933. https://doi.org/10.1039/b601840h.

(13) Gasser, G.; Ott, I.; Metzler-Nolte, N. Organometallic Anticancer Compounds. J. Med. Chem. 2011, 54 (1), 3-25. https://doi.org/10.1021/jm100020w.

(14) Gianferrara, T.; Bratsos, I.; Alessio, E. A Categorization of Metal Anticancer Compounds Based on Their Mode of Action. Dalton Trans. 2009, No. 37, 75887598. https://doi.org/10.1039/b905798f.

(15) Alessio, E.; Messori, L. NAMI-A and KP1019/1339, Two Iconic Ruthenium Anticancer Drug Candidates Face-to-Face: A Case Story in Medicinal Inorganic Chemistry. Molecules 2019, 24, 1995.

(16) Sava, G.; Capozzi, I.; Clerici, K.; Gagliardi, G.; Alessio, E.; Mestroni, G. Pharmacological Control of Lung Metastases of Solid Tumours by a Novel Ruthenium Complex. Clin. Exp. Metastasis 1998, 16 (4), 371-379. https://doi.org/10.1023/A:1006521715400.

(17) Lentz, F.; Drescher, A.; Lindauer, A.; Henke, M.; Hilger, R. a; Hartinger, C. G.; Scheulen, M. E.; Dittrich, C.; Keppler, B. K.; Jaehde, U. Pharmacokinetics of a Novel Anticancer Ruthenium Complex (KP1019, FFC14A) in a Phase I DoseEscalation Study. Anticancer. Drugs 2009, 20 (2), 97-103. https://doi.org/10.1097/CAD.0b013e328322fbc5.

(18) Trondl, R.; Heffeter, P.; Kowol, C. R.; Jakupec, M. a.; Berger, W.; Keppler, B. K. NKP-1339, the First Ruthenium-Based Anticancer Drug on the Edge to Clinical Application. Chem. Sci. 2014, 5 (8), 2925-2932. https://doi.org/10.1039/c3sc53243g.

(19) Hartinger, C. G.; Zorbas-Seifried, S.; Jakupec, M. A.; Kynast, B.; Zorbas, H.; Keppler, B. K. From Bench to Bedside - Preclinical and Early Clinical Development of the Anticancer Agent Indazolium Trans-[Tetrachlorobis(1HIndazole)Ruthenate(III)] (KP1019 or FFC14A). J. Inorg. Biochem. 2006, 100 
(5-6), 891-904. https://doi.org/10.1016/j.jinorgbio.2006.02.013.

(20) Yin, H.; Roque, J.; Konda, P.; Monro, S.; Colo, K. L.; Gujar, S.; Thummel, R. P.; Lilge, L.; Cameron, C. G.; Mcfarland, S. A. Transition Metal Complexes and Photodynamic Therapy from a Tumor-Centered Approach: Challenges, Opportunities, and Highlights from the Development of TLD1433. Chem. Rev. 2019, 119, 797-828. https://doi.org/10.1021/acs.chemrev.8b00211.

(21) Notaro, A.; Gasser, G. Monomeric and Dimeric Coordinatively Saturated and Substitutionally Inert $\mathrm{Ru}(\mathrm{II})$ Polypyridyl Complexes as Anticancer Drug Candidates. Chem. Soc. Rev. 2017, 46 (23), 7317-7337. https://doi.org/10.1039/c7cs00356k.

(22) Zeng, L.; Gupta, P.; Chen, Y.; Wang, E.; Ji, L.; Chao, H.; Chen, Z.-S.; Mai, J.; Zhang, H.; Li, Z.; et al. The Development of Anticancer Ruthenium( Ii ) Complexes: From Single Molecule Compounds to Nanomaterials. Chem. Soc. Rev. 2017, 46 (19), 5771-5804. https://doi.org/10.1039/C7CS00195A.

(23) Schatzschneider, U.; Niesel, J.; Ott, I.; Gust, R.; Alborzinia, H.; Wölfl, S. Cellular Uptake, Cytotoxicity, and Metabolic Profiling of Human Cancer Cells Treated with Ruthenium(II) Polypyridyl Complexes [Ru(Bpy) 2(N-N)]Cl2 with N-N=bpy, Phen, Dpq, Dppz, and Dppn. ChemMedChem 2008, 3 (7), 1104-1109. https://doi.org/10.1002/cmdc.200800039.

(24) Gill, M. R.; Derrat, H.; Smythe, C. G. W.; Battaglia, G.; Thomas, J. A. Ruthenium(II) Metallo-Intercalators: DNA Imaging and Cytotoxicity. ChemBioChem 2011, 12 (6), 877-880. https://doi.org/10.1002/cbic.201000782.

(25) Du, K. J.; Wang, J. Q.; Kou, J. F.; Li, G. Y.; Wang, L. L.; Chao, H.; Ji, L. N. Synthesis, DNA-Binding and Topoisomerase Inhibitory Activity of Ruthenium(II) Polypyridyl Complexes. Eur. J. Med. Chem. 2011, 46 (4), 10561065. https://doi.org/10.1016/j.ejmech.2011.01.019.

(26) Pisani, M. J.; Weber, D. K.; Heimann, K.; Collins, J. G.; Keene, F. R. Selective Mitochondrial Accumulation of Cytotoxic Dinuclear Polypyridyl Ruthenium(II) Complexes. Metallomics 2010, 2 (6), 357-432. https://doi.org/10.1039/c004922k. 
(27) Pisani, M. J.; Fromm, P. D.; Mulyana, Y.; Clarke, R. J.; Körner, H.; Heimann, K.; Collins, J. G.; Keene, F. R. Mechanism of Cytotoxicity and Cellular Uptake of Lipophilic Inert Dinuclear Polypyridylruthenium(II) Complexes. ChemMedChem 2011, 6 (5), 848-858. https://doi.org/10.1002/cmdc.201100053.

(28) Ye, R. R.; Ke, Z. F.; Tan, C. P.; He, L.; Ji, L. N.; Mao, Z. W. HistoneDeacetylase-Targeted Fluorescent Ruthenium(II) Polypyridyl Complexes as Potent Anticancer Agents. Chem. - A Eur. J. 2013, 19 (31), 10160-10169. https://doi.org/10.1002/chem.201300814.

(29) Notaro, A.; Frei, A.; Rubbiani, R.; Jakubaszek, M.; Basu, U.; Koch, S.; Mari, C.; Dotou, M.; Blacque, O.; Gouyon, J.; et al. A Ruthenium(II) Complex Containing a Redox-Active Semiquinonate Ligand as Potential Chemotherapeutic Agent: From Synthesis to In Vivo Studies. ChemRxiv. Prepr. 2019. https://doi.org/10.26434/chemrxiv.9582527.v1.

(30) Vlček, A. Metal and Ligand Oxidation States in Dioxolene Complexes: Meaning, Assignment and Control. Comments Inorg. Chem. 1994, 16 (4), 207228. https://doi.org/10.1080/02603599408035860.

(31) Wheeler, D. E.; Rodriguez, J. H.; Mccusker, J. K. Density Functional Theory Analysis of Electronic Structure Variations across the Orthoquinone / Semiquinone / Catechol Redox Series. 1999, 4101-4112. https://doi.org/10.1021/jp990166q.

(32) Ward, M. D.; Mccleverty, J. A.; Ward, M. D. Non-Innocent Behaviour in Mononuclear and Polynuclear Complexes: Consequences for Redox and Electronic Spectroscopic Properties. J. chem. soc. Dalt. Trans. 2002, 275-288. https://doi.org/10.1039/b110131p.

(33) Baell, J. B. Feeling Nature ' s PAINS: Natural Products, Natural Product Drugs, and Pan Assay Interference Compounds (PAINS). J. Nat. Prod. 2016, 79, 616628. https://doi.org/10.1021/acs.jnatprod.5b00947.

(34) Tsai, M.; Rochford, J.; Polyansky, D. E.; Wada, T.; Tanaka, K.; Fujita, E.; Muckerman, J. T. Characterization of Redox States of Ru ( OH 2 )( Q )( Tpy ) 2 + ( Q ) Related Species through Experimental and Theoretical Studies. Inorg 
Chem 2009, 48 (10), 4372-4383.

(35) Sofen, S. R.; Ware, D. C.; Cooper, S. R.; Raymond, K. N. Structural , Electrochemical, and Magnetic Properties of a Four-Membered Redox Series 03 ) in Catechol-Benzoquinone Complexes of Chromium ([ Cr ( L3 ) F “,. Inorg. Chem. 1979, 18 (2), 234-239. https://doi.org/10.1021/ic50192a006.

(36) Zhao, H. C.; Fu, B.; Schweinfurth, D.; Harney, J. P.; Sarkar, B.; Tsai, M.; Rochford, J. Tuning Oxyquinolate Non-Innocence at the Ruthenium Polypyridyl Core. Eur. J. Inorg. Chem. 2013, 2, 4410-4420. https://doi.org/10.1002/ejic.201300373.

(37) Ingram, J. D.; Costa, P. J.; Adams, H.; Ward, M. D.; Félix, V.; Thomas, J. A. Ruthenium(II) Thiacrown Complexes Incorporating Noninnocent Redox Active Ligands: Synthesis, Electrochemical Properties, and Theoretical Studies And. Inorg. Chem. 2012, 51, 10483-10494.

(38) Haga, M.; Dodsworth, E. S.; Lever, A. B. P. Catechol-Quinone Redox Series Involving Bis (Bipyridine) Ruthenium (II) and Tetrakis (Pyridine) Rutbenium (II). Inorg. Chem. 1986, 25 (4), 447-453. https://doi.org/10.1021/ic00224a013.

(39) Damas, A.; Ventura, B.; Moussa, J.; Degli Esposti, Alessandra Chamoreau, L.M.; Barbieri, A.; Amouri, H. Turning on Red and Near-Infrared Phosphorescence in Octahedral Complexes with Metalated Quinones. Inorg. Chem. 2012, 51, 1739-1750. https://doi.org/10.1021/ic202021w.

(40) Kessel, S. L.; Emberson, R. M.; Debrunner, P. G.; Hendrickson, D. N. Iron ( III ), Manganese ( III ), and Cobalt ( II1 ) Complexes with Single Chelating o Semiquinone Ligands. Inorg. Chem. 1980, No. Iii, 1170-1178.

(41) Remenyi, C.; Kaupp, M.; Hubland, A. Where Is the Spin? Understanding Electronic Structure and g-Tensors for Ruthenium Complexes with RedoxActive Quinonoid Ligands. J. Am. Chem. Soc. 2005, 127 (8), 11399-11413. https://doi.org/10.1021/ja051811b.

(42) Wada, T.; Yamanaka, M.; Fujihara, T.; Miyazato, Y.; Tanaka, K. Experimental and Theoretical Evaluation of the Charge Distribution over the Ruthenium and Dioxolene Framework of $\left[\mathrm{Ru}(\mathrm{OAc})(\right.$ Dioxolene)(Terpy) $]$ (Terpy $=2,2^{\prime}: 6^{\prime}, 2^{\prime \prime}-$ 
Terpyridine) Depending on the Substituents. Inorg. Chem. 2006, 45 (22), 88878894. https://doi.org/10.1021/ic060696i.

(43) Notaro, A.; Gasser, G.; Castonguay, A. Note of Caution for the Aqueous Behaviour of Metal-Based Drug Candidates. ChemMedChem n/a (n/a). https://doi.org/10.1002/cmdc.201900677.

(44) Brastos, I.; Alessio, E.; Ringenberg, M. E.; Rauchfuss, T. B. Ruthenium Complexes. Inorg. Synth. 2010, 35 (Ii), 148-163. https://doi.org/10.1002/9780470651568.ch8.

(45) Caspar, R.; Cordier, C.; Waern, J. B.; Guyard-Duhayon, C.; Gruselle, M.; Le Floch, P.; Amouri, H. A New Family of Mono- and Dicarboxylic Ruthenium Complexes [Ru(DIP) 2 (L 2 )] 2+ (DIP = 4,7-Diphenyl-1,10-Phenanthroline): Synthesis, Solution Behavior, and X-Ray Molecular Structure of Trans [Ru(DIP) 2 (MeOH) 2 ][OTf] 2. Inorg. Chem. 2006, 45 (10), 4071-4078. https://doi.org/10.1021/ic0601236.

(46) Masui, H.; Lever, A. B. P.; Auburn, P. R. Control of Orbital Mixing in Ruthenium Complexes Containing Quinone-Related Ligands. Inorg. Chem. 1991, 30, 2402-2410. https://doi.org/10.1021/ic00010a033.

(47) Allard, M. M.; Odongo, O. S.; Lee, M. M.; Chen, Y.; Endicott, J. F.; Schlegel, H. B. Effects of Electronic Mixing in Ruthenium ( II ) Complexes with Two Equivalent Acceptor Ligands . Spectroscopic , Electrochemical , and Computational Studies. Inorg. Chem. 2010, 49, 6840-6852. https://doi.org/10.1021/ic100202h.

(48) Schafer, F. Q.; Buettner, G. R. Redox Environment of the Cell as Viewed Through the Redox State of the Glutathione Disulfide/Glutatione Couple. Free Radic. Biol. Med. 2001, 30 (11), 1191-1212.

(49) Connelly, N. G.; Geiger, W. E. Chemical Redox Agents for Organometallic Chemistry. Chem. Rev. 1996, 96, 877-910.

(50) Chakraborty, S.; Laye, R. H.; Paul, R. L.; Gonnade, R. G.; Puranik, V. G.; Ward, D.; Kumar, G. Spectroelectrochemical Properties. J. Chem. Soc., Dalt. Trans. 2002, 1172-1179. https://doi.org/10.1039/b107307a. 
(51) Patra, M.; Joshi, T.; Pierroz, V.; Ingram, K.; Kaiser, M. DMSO-Mediated Ligand Dissociation : Renaissance for Biological Activity Of. Chem. Eur. J. 2013, 19, 14768-14772. https://doi.org/10.1002/chem.201303341.

(52) Hall, M. D.; Telma, K. A.; Chang, K.-E.; Lee, T. D.; Madigan, J. P.; Lloyd, J. R.; Goldlust, I. S.; Hoeschele, James D. Gottesman, M. M. Say No to DMSO: Dimethylsulfoxide Inactivates Cisplatin, Carboplatin and Other Platinum Complexes. Cancer Res. 2014, 74 (14), 3913-3922. https://doi.org/10.1158/0008-5472.CAN-14-0247.Say.

(53) Huang, H.; Humbert, N.; Bizet, V.; Patra, M.; Chao, H. Influence of the Dissolution Solvent on the Cytotoxicity of Octahedral Cationic Ir ( III ) Hydride Complexes. J. Organomet. Chem. 2017, 839, 15-18. https://doi.org/10.1016/j.jorganchem.2016.12.010.

(54) Frei, A.; Rubbiani, R.; Tubafard, S.; Blacque, O.; Anstaett, P.; Felgenträger, A.; Maisch, T.; Spiccia, L.; Gasser, G. Synthesis, Characterization, and Biological Evaluation of New RU(Ii) Polypyridyl Photosensitizers for Photodynamic Therapy. J. Med. Chem. 2014, 57 (17), 7280-7292. https://doi.org/10.1021/jm500566f.

(55) Cepeda, V.; Fuertes, M.; Castilla, J.; Alonso, C.; Quevedo, C.; Perez, J. Biochemical Mechanisms of Cisplatin Cytotoxicity. Anticancer. Agents Med. Chem. 2007, 7 (1), 3-18. https://doi.org/10.2174/187152007779314044.

(56) Keizer, H. G.; Pinedo, H. M.; Schuurhuis, G. J.; Joenje, H. DOXORUBICIN (ADRIAMYCIN): A CRITICAL REVIEW OF FREE RADICALDEPENDENT MECHANISMS OF CYTOTOXICITY. Pharmac. Ther 1990, 47, 219-231. https://doi.org/10.1016/0163-7258(90)90088-J.

(57) Kelm, J. M.; Timmins, N. E.; Brown, C. J.; Fussenegger, M.; Nielsen, L. K. Multicellular Tumor Spheroids Applicable to a Wide Variety of Cell Types. Biotechnol. Bioeng. 2003, 83 (2), 173-180. https://doi.org/10.1002/bit.10655.

(58) Kapałczyńska, M.; Kolenda, T.; Przybyła, Weronika Zajączkowska, Maria Teresiak, A.; Filas, V.; Ibbs, M.; Bliźniak, R.; Łuczewski, Łukasz Lamperska, K. State of the Art Paper 2D and 3D Cell Cultures - a Comparison of Different 
Types of Cancer Cell Cultures. Arch. Med. Sci. 2018, 4, 910-919. https://doi.org/https://doi.org/10.5114/aoms.2016.63743.

(59) Ma, H.; Jiang, Q.; Han, S.; Wu, Y.; Tomshine, J. C.; Wang, D.; Gan, Y.; Zou, G. Multicellular Tumor Spheroids as an In Vivo - Like Tumor Model for ThreeDimensional Imaging Of. Mol. Imaging 2012, 11 (6), 487-498. https://doi.org/10.2310/7290.2012.00012.

(60) Friedrich, J.; Seidel, C.; Ebner, R.; Kunz-schughart, L. A. Spheroid-Based Drug Screen : Considerations and Practical Approach. Nat. Protoc. 2009, 4 (3), 309324. https://doi.org/10.1038/nprot.2008.226.

(61) Hess, J.; Huang, H.; Kaiser, A.; Pierroz, V.; Blacque, O. Evaluation of the Medicinal Potential of Two Ruthenium ( II ) Polypyridine Complexes as Oneand Two-Photon Photodynamic Therapy Photosensitizers. Chem. A Eur. J. 2017, No. Ii, 9888-9896. https://doi.org/10.1002/chem.201701392.

(62) Seo, O. W.; Kim, M.; Hulme, J.; An, S. S. A. Monitoring the Effects of Doxorubicin on 3D-Spheroid Tumor Cells in Real-Time. 2016, 7207-7218.

(63) Ricci, M. S.; Zong, W. Chemotherapeutic Approaches for Targeting Cell Death Pathways. Oncologist 2006, 11, 342-357.

(64) Elmore, S. Apoptosis: A Review of Programmed Cell Death. Toxicol. Pathol. 2007, 35, 495-516. https://doi.org/10.1080/01926230701320337.

(65) Zeng, L.; Chen, Y.; Huang, H.; Wang, J.; Zhao, D.; Ji, L.; Chao, H. Cyclometalated Ruthenium(II) Anthraquinone Complexes Exhibit Strong Anticancer Activity in Hypoxic Tumor Cells. Chemistry 2015, 21 (43), 1530815319. https://doi.org/10.1002/chem.201502154.

(66) Zisowsky, J.; Koegel, S.; Leyers, S.; Devarakonda, K.; Kassack, M. U.; Osmak, M.; Jaehde, U. Relevance of Drug Uptake and Efflux for Cisplatin Sensitivity of Tumor Cells. Biochem. Pharmacol. 2007, 73 (2), 298-307. https://doi.org/10.1016/j.bcp.2006.10.003.

(67) Dong, Y.; Berners-price, S. J.; Thorburn, D. R.; Antalis, T.; Dickinson, J.; Hurst, T.; Qiu, L.; Khoo, S. K.; Parsons, P. G. Serine Protease Inhibition and 
Mitochondrial Dysfunction Associated with Cisplatin Resistance in Human Tumor Cell Lines : Targets for Therapy. Biochem. Pharmacol. 1997, 53, 16731682.

(68) Zorova, L. D.; Popkov, V. A.; Plotnikov, E. Y.; Silachev, D. N.; Pevzner, B.; Jankauskas, S. S.; Babenko, V. A.; Zorov, S. D.; Balakireva, A. V; Juhaszova, M.; et al. Mitochondrial Membrane Potential. Anal. Biochem. 2018, No. 552, 50-59. https://doi.org/10.1016/j.ab.2017.07.009.

(69) Dedov, V. N.; Cox, G. C.; Roufogalis, B. D. Visualisation of Mitochondria in Living Neurons with Single- and Two-Photon ${ }^{-}$Uorescence Laser Microscopy. Micron 2001, 32, 653-660.

(70) Sakamuru, S.; Attene-ramos, M. S.; Xia, M. Mitochondrial Membrane Potential Assay. In High-Throughput Screening Assays in Toxicology, Methods in Molecular Biology,; 2016; Vol. 1473, pp 17-22. https://doi.org/10.1007/978-14939-6346-1.

(71) Singla, A. K.; Garg, A.; Aggarwal, D. Paclitaxel and Its Formulations. Int. J. Pharm. 2002, 253, 179-192. https://doi.org/10.1016/S0378-5173(01)00986-3.

(72) Engels, F.; Mathot, R.; Verweij, J. Alternative Drug Formulations of Docetaxel: A Review. Anticancer. Drugs 2007, 18 (2), 95-103. https://doi.org/10.1097/CAD.0b013e3280113338.

(73) Rowe, R. C.; Sheskey, P. J.; Cook, W. G.; Quinn, M. E. Handbook of Pharmaceutical Excipients - 7th Edition. Pharm. Dev. Technol. 2013, 18 (2), 544. https://doi.org/10.3109/10837450.2012.751408.

(74) Zeng, Z. W.; Zhou, G. L.; Wang, J. J.; Li, F. Z.; Wang, A. M. Recent Advances in PEG - PLA Block Copolymer Nanoparticles. Int. J. Nanomedicine 2010, 1057-1065. https://doi.org/10.2147/IJN.S14912.

(75) Zhang, H. Thin-Film Hydration Followed by Extrusion Method for Liposome Preparation. Methods Mol. Biol. 2017, 1522, 17-22. https://doi.org/10.1007/978-1-4939-6591-5_2.

(76) Montfoort, J. E. van; Hagenbuch, B.; Groothuis, G. M. M.; Koepsell, H.; Meier, 
P. J.; Meijer, D. K. F. Drug Uptake Systems in Liver and Kidney. Curr. Drug Metab. 2003, 4 (3), 185-211. https://doi.org/10.2174/1389200033489460.

(77) Casazza, A. M.; Pratesi, G.; Giuliani, F.; Formelli, F.; Marco, A. Di. Enhancement of the Antitumor Activity of Adriamycin by Tween 80. Tumori J. 1978, 64 (2), 115-129. https://doi.org/10.1177/030089167806400202.

(78) Lorenz, W.; Schmal, A.; Schult, H.; Lang, S.; Ohmann, C.; Weber, D.; Kapp, B.; Lüben, L.; Doenicke, A. Histamine Release and Hypotensive Reactions in Dogs by Solubilizing Agents and Fatty Acids: Analysis of Various Components in Cremophor El and Development of a Compound with Reduced Toxicity. Agents Actions 1982, 12 (1-2), 64-80. https://doi.org/10.1007/BF01965109.

(79) Bergh, M.; Magnusson, K.; Nilsson, J. L. G.; Karlberg, A.-T. Contact Allergenic Activity of Tween ${ }^{\circledR} 80$ before and after Air Exposure. Contact Dermatitis 1997, 37 (1), 9-18. https://doi.org/10.1111/j.1600-0536.1997.tb00368.x.

(80) Fulmer, G. R.; Miller, A. J. M.; Sherden, N. H.; Gottlieb, H. E.; Nudelman, A.; Stoltz, B. M.; Bercaw, J. E.; Goldberg, K. I. NMR Chemical Shifts of Trace Impurities: Common Laboratory Solvents, Organics, and Gases in Deuterated Solvents Relevant to the Organometallic Chemist. Organometallics 2010, 29 (9), 2176-2179. https://doi.org/10.1021/om100106e.

(81) Gaussian16 Revision C.01; Frisch, M. J.; Trucks, G. W.; Schlegel, H. B.; Scuseria, G. E.; Robb, M. A.; Cheeseman, J. R.; Scalmani, G.; Barone, V.; Petersson, G. A.; et al. Gaussian16 Revision C.01. 2016.

(82) Von Bart, U.; Hedin, L. A Local Exchange-Correlation Potential for the Spin Polarized Case : I. J. Phys. C Solid State Phys. 1972, 5, 1629.

(83) Parr, R. G.; Weito, Y. Density-Functional Theory of Atoms and Molecules; Press, O. U., Ed.; Oxford University Press.

(84) Ditchfield, R.; Hehre, W. J.; Pople, J. A. SelfConsistent MolecularOrbital Methods . IX . An Extended GaussianType Basis for MolecularOrbital Studies of Organic Molecules. J. Chem. Phys. 1971, 54, 724. https://doi.org/10.1063/1.1674902. 
(85) Hehre, W. J.; Ditchfield, R.; Pople, J. A. Self — Consistent Molecular Orbital Methods . XII . Further Extensions of Gaussian - Type Basis Sets for Use in Molecular Orbital Studies of Organic Molecules. J. Chem. Phys. 1972, 56 (May 2012), 2257. https://doi.org/10.1063/1.1677527.

(86) Hariharan, P. C.; Pople, J. A. The Influence of Polarization Functions on Molecular Orbital Hydrogenation Energies. Theor. chim. Acta 1973, 28, 213222.

(87) Becke, A. D. Density-Functional Thermochemistry . III . The Role of Exact Exchange. J. Chem. Phys. 1993, 98, 5648. https://doi.org/10.1063/1.464913.

(88) Scalmani, G.; Frisch, M. J. Continuous Surface Charge Polarizable Continuum Models of Solvation. I . General Formalism Continuous Surface Charge Polarizable Continuum Models of Solvation . I . General Formalism. J. Chem. Phys. 2010, 132, 114110. https://doi.org/10.1063/1.3359469.

(89) Neese, F. ORCA-an Ab Initio, Density Functional and Semiempirical Program Package; 2007; Vol. 26-35.

(90) Lenthe, E. Van; Ehlers, A.; Baerends, E. Geometry Optimizations in the Zero Order Regular Approximation for Relativistic Effects. J. Chem. Phys. 1999, 110, 8943. https://doi.org/10.1063/1.478813.

(91) Wüllen, C. Van. Molecular Density Functional Calculations in the Regular Relativistic Approximation: Method, Application to Coinage Metal Diatomics , Hydrides, Fluorides and Chlorides, and Comparison with First-Order Relativistic Calculations Molecular Density Functi. J. Chem. Phys. 1998, 109, 392. https://doi.org/10.1063/1.476576.

(92) Pantazis, D. A.; Chen, X.; Landis, C. R.; Neese, F. All-Electron Scalar Relativistic Basis Sets for Third-Row Transition Metal Atoms. J. Chem. Theory Comput. 2008, 4, 908-919.

(93) Neese, F.; Wennmohs, F.; Hansen, A.; Becker, U. Efficient, Approximate and Parallel Hartree-Fock and Hybrid DFT Calculations. A 'Chain-of-Spheres' Algorithm for the Hartree-Fock Exchange. Chem. Phys. 2009, 356, 98-109. 
(94) Weigend, F. Accurate Coulomb-Fitting Basis Sets for H to Rn. Phys. Chem. Chem. Phys. 2006, 8, 1057-1065. https://doi.org/10.1039/b515623h.

(95) Klamt, A.; Schuurmann, G. COSMO : A New Approach to Dielectric Screening in Solvents with Explicit. J. Chem.Soc. Perkin Trans. 1993, 5, 799-805.

(96) Stoll, S.; Schweiger, A. EasySpin, a Comprehensive Software Package for Spectral Simulation and Analysis in EPR. J. Magn. Reson. 2006, 178, 42-55. https://doi.org/10.1016/j.jmr.2005.08.013.

(97) Bao, D.; Millare, B.; Xia, W.; Steyer, B. G.; Gerasimenko, A. A.; Ferreira, A.; Contreras, A.; Vullev, V. I. Electrochemical Oxidation of Ferrocene : A Strong Dependence on the Concentration of the Supporting Electrolyte for Nonpolar Solvents. J. Phys. Chem. A 2009, 2, 1259-1267.

(98) Krejeik, M.; Dangk, M.; Hartl, F. Simple Construction of an Infrared Optically Transparent Thin-Layer Electrochemical Cell Applications to the Redox Reactions of Ferrocene , Mn ,( CO ) 1o. J. Electroanal. Chem., 1991, 317, 179187.

(99) Https://rockland-inc.com/Nuclear-Extract-Protocol.aspx. (accessed the 03.10.2019).

(100) Tharaud, M.; Gardoll, S.; Khelifi, O.; Benedetti, M. F.; Sivry, Y. UFREASI: User-FRiendly Elemental DAta ProcesSIng. A Free and Easy-to-Use Tool for Elemental Data Treatment. Microchem. J. 2015, 121, 32-40. https://doi.org/10.1016/j.microc.2015.01.011. 